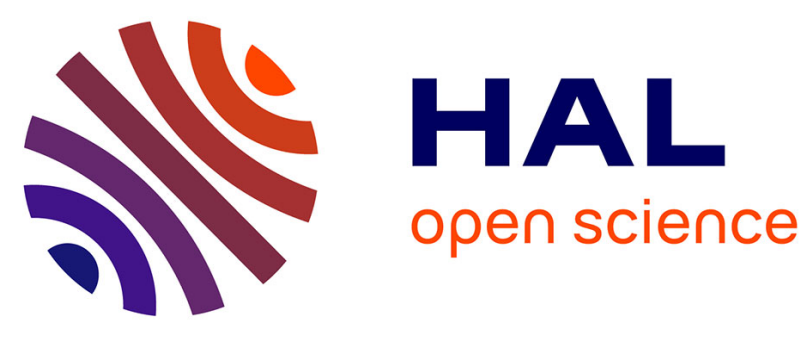

\title{
Water storage changes as a marker for base flow generation processes in a tropical humid basement catchment (Benin): Insights from hybrid gravimetry
}

Basile Hector, Luc Séguis, Jacques Hinderer, Jean-Martial Cohard, Maxime Wubda, Marc Descloitres, Nathalie Benarrosh, Jean-Paul Boy

\section{To cite this version:}

Basile Hector, Luc Séguis, Jacques Hinderer, Jean-Martial Cohard, Maxime Wubda, et al.. Water storage changes as a marker for base flow generation processes in a tropical humid basement catchment (Benin): Insights from hybrid gravimetry. Water Resources Research, 2015, 51 (10), pp.8331-8361 10.1002/2014WR015773 . hal-01292383

\section{HAL Id: hal-01292383 https://hal.science/hal-01292383}

Submitted on 23 Mar 2016

HAL is a multi-disciplinary open access archive for the deposit and dissemination of scientific research documents, whether they are published or not. The documents may come from teaching and research institutions in France or abroad, or from public or private research centers.
L'archive ouverte pluridisciplinaire HAL, est destinée au dépôt et à la diffusion de documents scientifiques de niveau recherche, publiés ou non, émanant des établissements d'enseignement et de recherche français ou étrangers, des laboratoires publics ou privés. 


\section{Water Resources Research}

\section{RESEARCH ARTICLE \\ 10.1002/2014WR015773 \\ Key Points: \\ Water storage changes as a marker for base flow generation processes in a tropical humid basement catchment (Benin): Insights from hybrid gravimetry}

- Hybrid gravity and neutron probe

data show similar space-time storage

patterns

- Storage change patterns are related

to lithology derived from geophysics and drill logs

- Storage change observations helped to derive a conceptual model for the catchment hydrology

Correspondence to:

B. Hector,

basilehector@gmail.com

Citation:

Hector, B., L. Séguis, J. Hinderer, J.-M. Cohard, M. Wubda, M. Descloitres, N. Benarrosh, and J.-P. Boy (2015), Water storage changes as a marker for base flow generation processes in a tropical humid basement catchment (Benin): Insights from hybrid gravimetry, Water Resour. Res., 51, 8331-8361, doi:10.1002/ 2014WR015773.

Received 28 APR 2014 Accepted 20 SEP 2015 Accepted article online 24 SEP 2015 Published online 23 OCT 2015

\author{
Basile Hector ${ }^{1}$, Luc Séguis², Jacques Hinderer'1, Jean-Martial Cohard ${ }^{3}$, Maxime Wubda4, \\ Marc Descloitres ${ }^{4}$, Nathalie Benarrosh², and Jean-Paul Boy ${ }^{1}$ \\ ${ }^{1}$ Institut de Physique du Globe de Strasbourg, UMR 7516 CNRS, Université de Strasbourg, Strasbourg, France, \\ ${ }^{2}$ Hydrosciences Montpellier UMR 5569 CNRS, IRD, Université de Montpellier, Montpellier, France, ${ }^{3}$ Laboratoire des \\ Transferts en Hydrologie et Environnement UMR 5564 CNRS, IRD, G-INP, Université Grenoble Alpes, Grenoble, France, \\ ${ }^{4}$ Laboratoire des Transferts en Hydrologie et Environnement UMR 5564 CNRS, IRD, G-INP, Université Grenoble Alpes, \\ Cotonou, Benin
}

\begin{abstract}
In basement catchments of subhumid West Africa, base flow is the main component of annual streamflow. However, the important heterogeneity of lithology hinders the understanding of base flow generation processes. Since these processes are linked with water storage changes (WSCs) across the catchment, we propose the use of hybrid gravity data in addition to neutron probe-derived water content and water levels to monitor spatiotemporal WSC of a typical crystalline basement headwater catchment (16 ha) in Benin. WSC behaviors are shown to provide insights into hydrological processes in terms of water redistribution toward the catchment outlet. Hybrid gravimetry produces gravity change observations from time-lapse microgravity surveys coupled with gravity changes monitored at a base station using a superconducting gravimeter and/or an absolute gravimeter. A dense microgravity campaign (70 surveys of 14 stations) covering three contrasted years was set up with a rigorous protocol, leading to low uncertainties ( $<2.5 \mu \mathrm{Gal}$ ) on station gravity determinations (with respect to the network reference station). Empirical orthogonal function analyses of both gravity changes and WSCs from neutron probe data show similar spatial patterns in the seasonal signal. Areas where storage and water table show a capping behavior (when data reach a plateau during the wet season), suggesting threshold-governed fast subsurface redistribution, are identified. This observed storage dynamics, together with geological structures investigated by electrical resistivity tomography and drill log analysis, make it possible to derive a conceptual model for the catchment hydrology.
\end{abstract}

\section{Introduction}

The amount of water stored within a catchment, together with its distribution from deep aquifers to the surface, is an important state variable of the hydrological system. In recent years, catchment storage has generated an increasing interest in the hydrology community, because of its central role in most hydrological processes from plot to catchment scales [e.g., Spence, 2010; McNamara et al., 2011; Tetzlaff et al., 2011].

Recent studies promoting the analysis of rainfall-streamflow relationships through storage measurements are based on data from temperate or cold climates, where it is acknowledged that storage dynamics determine streamflow generation mechanisms [McNamara et al., 2011; Tetzlaff et al., 2011]. Under a tropical humid climate, although the literature is much sparser [van De Giesen et al., 2000], it is often found that yearly streamflow amounts are dominated by subsurface flows [Bruijnzeel, 1983; Noguchi et al., 1997; Masiyandima et al., 2003; Giertz et al., 2006; Miguez-Macho and Fan, 2012], mostly due to high soil permeability. While saturation-excess overland flow is often observed in valley bottoms [Bruijnzeel, 1990], the overall predominance of subsurface flow calls for greater attention to the storage variable in these tropical environments.

Although storage is recognized as a fundamental state variable, many challenges arise around its monitoring, mostly based on point measurements, for which the representativeness is poor in heterogeneous landscapes. Spatial interpolation is therefore required, often assisted by geostatistical techniques [e.g., Bárdossy and Lehmann, 1998; Perry and Niemann, 2008]. Most techniques depend on instrument calibration (e.g., 
time domain reflectometry probes, neutron probes), a major issue for the monitoring of deep water storage changes. Catchment-scale storage can also be observed using a water balance approach with streamflow measurements [Kirchner, 2009], but this method gives no insight into internal variability. Furthermore, errors from each budget component combine and propagate to the storage estimates, which is an important limitation of such methods. Tracers combined with hydrological modeling provide insights into storage distribution at the catchment scale [e.g., Birkel et al., 2011; Seibert et al., 2011], but eventually rely on model assumptions. Finally, field studies focusing on storage are often limited to shallow soil moisture and/or groundwater, but rarely consider the whole column, because few techniques allow this inference. Current techniques clearly lack for the ability to infer water storage from plot to catchment scales.

In the "future directions" section of their paper on storage as a metric for catchment comparison, McNamara et al. [2011] mentioned new geophysical methods such as microgravity as an additional way to evaluate water storage. The main applications to hydrology of time-lapse microgravity surveys are (1) specific yield estimates [Montgomery, 1971; Lambert and Beaumont, 1977; Cole, 1991; Pool and Eychaner, 1995; Howle et al., 2003; Pool, 2008; Gehman et al., 2009], (2) monitoring water storage changes (WSCs) on specific areas for process identification or water budget estimates [Whitcomb et al., 1980; Naujoks et al., 2008; Chapman et al., 2008; Gettings et al., 2008; McClymont et al., 2012; Pfeffer et al., 2013], and (3) calibration-validation of conceptual or physically based hydrological models [Chapman et al., 2008; Naujoks et al., 2010; Christiansen et al., 2011a,2011b]. Only few studies used gravity data to address the link between WSCs and discharge [Jacob et al., 2008; Lampitelli and Francis, 2010; Kroner and Weise, 2011; Creutzfeldt et al., 2012, 2014].

Microgravimeters are instruments able to measure gravity variations as low as few $\mu$ Gal [Brown and Rymer, 1991] and include spring gravimeters, absolute gravimeters (AG) and superconducting gravimeters (SG). Spring microgravimeters can only monitor changes in the spatial distribution of water storage with respect to a base station or a network mean value, without contributing any information on the time changes of the network's mean value [Pfeffer et al., 2013]. Hybrid gravimetry is the joint use of spring microgravimeters with instruments providing changes at the base station (i.e., SG, measuring continuously, and AG, such as the FG5, measuring episodically), in order to determine the absolute changes at all points of the network [Pool et al., 2000; Okubo et al., 2002; Sugihara and Ishido, 2008; Pool and Anderson, 2008] and therefore the active storage component of the catchment [McNamara et al., 2011].

The particular advantage of gravity data is that it integrates all mass variations within the instrument support volume (footprint), and therefore gives access to integrated WSC values. When using gravimeters to measure shallow water storage changes, the footprint (the area where $90 \%$ of the signal originates) typically ranges from a few dozen meters around the instrument up to kilometers in areas with marked topography [Meurers et al., 2007; Creutzfeldt et al., 2008; Masson et al., 2012; Hector et al., 2014]. This is comparable to footprints of instruments devoted to evapotranspiration, an important component of the water budget, such as Eddy-covariance stations or large-aperture scintillometers [e.g., Guyot et al., 2009]. The integrated nature of gravity data is also its main drawback, given that it can be challenging to identify signal sources. In a way, time-lapse gravimetry measures all mass changes but hardly distinguishes anything.

In this paper, we study a small catchment in northern Benin, a Sudanian region in West Africa. Processes governing rainfall-streamflow relationships are of primary importance for understanding the resilience to both climate change and increasing human pressure in this area, and are still poorly known. West Africa experienced a severe and long-lasting drought in 1970-1990, with a precipitation deficit of about 30\% in the Sahel region, north of the Sudanian area, and slightly less in the Sudanian region. Hydrological responses differed greatly between these two regions. In Sahel, the drought coincided with an observed increase in flow [Leblanc et al., 2008; Mahé and Paturel, 2009; Gardelle et al., 2010]. This paradox has been explained by simultaneous land clearance [Favreau et al., 2009] during extensive agriculture development. This resulted in a modification in soil crusting and hence decreasing surface permeability, increasing infiltration-excess (Hortonian) runoff, the major streamflow generation process in the Sahel [Casenave and Valentin, 1992; Séguis et al., 2004]. In the Sudanian region, a substantial drop in streamflow was observed, about twice as large as the precipitation deficit, e.g., a 40\% streamflow deficit versus a 15-20\% precipitation deficit in the upper Ouémé catchment in Benin [Lebel and Vischel, 2005; Descroix et al., 2009]. In this area, infiltration rates are higher than in the Sahel [Valentin et al., 2004], and streamflow is governed by deep and shallow subsurface flow with a minor contribution from Hortonian flow and saturation overland flow [Masiyandima et al., 2003; Giertz et al., 2006; Kamagaté et al., 2007; Séguis et al., 2011a]. Despite this understanding, the hydrology of the Sudanian area is not yet fully 
understood, which prevents the community from anticipating system responses to expected climate changes and increasing human pressure on land cover.

Previous gravimetric studies in the area focused on the footprint zone ( $<100 \mathrm{~m}$, a "plot" scale) of a FG5 AG instrument and nearby SG [Hector et al., 2013, 2014], installed within the GHYRAF (Gravity and Hydrology in Africa) project [Hinderer et al., 2009, 2012]. The observed WSCs showed some discrepancies between point neutron probe (NP) measurements and integrative gravity measurements, partly due to NP calibration issues. Regardless to this, mechanisms controlling WSCs could not be properly understood particularly because of unknown boundary conditions (i.e., lateral water transfers to and from the plot scale) and despite important physically based modeling efforts [Hector, 2014]. WSCs and associated water redistribution processes at the catchment scale where budgets can be closed therefore need to be assessed. We investigate herein the potential of hybrid gravity measurements to derive WSC behaviors across the catchment.

We present and discuss a unique and dense data set for WSC estimates composed of water table data, NP data (and derived water storage estimates), and hybrid gravity data at a headwater catchment scale $\left(0.16 \mathrm{~km}^{2}\right)$ in a subhumid Sudanian area. The first part reports the material available. An appendix includes the detailed acquisition protocol and processing of microgravity data, which are fundamental to determine the accuracy of the method, but can be skipped by the reader who is not interested in such technical aspects. Then results are provided and different spatiotemporal WSC estimates are compared by means of empirical orthogonal functions (EOFs), particularly well suited for the extraction of coherent time and space patterns in the data. Typical WSC behaviors are identified and related to lithological structure patterns which are further investigated by electrical resistivity tomography and borehole log analysis. This made it possible to build a conceptual model for the catchment hydrology.

\section{Study Area}

The small experimental head catchment of Nalohou $\left(0.16 \mathrm{~km}^{2}\right)$ belongs to the upper Ouémé catchment in northern Benin $\left(14,000 \mathrm{~km}^{2}\right.$ see Figures 1a and 1b) with a humid Sudanian-type climate. The upper Ouémé was chosen as a meso-scale site for hydrological monitoring and accurate water budget estimates within the AMMA-CATCH multidisciplinary project around the West-African monsoon system and its coupling with the continental water cycle [Lebel et al., 2009]. A dense monitoring network dedicated to water redistribution process studies has been set up since 2003 on the small catchment close to the village of Nalohou (Figures 1c and 1d).

Nalohou catchment is a typical first-order catchment of the Sudanian area composed of hillslopes which converge on a seasonally saturated linear low-land, referred to as a bas-fond, leading to a first-order channel (Figure 1d). Bas-fonds are common features in the landscape, as exhibited for instance in Figure 1c, where other bas-fonds from the first-order rivers of the Ara catchment are shown. An unconfined aquifer is located in a weathered layer 7-22 m thick [Kamagaté et al., 2007; Descloitres et al., 2011] developed over a metamorphic basement (gneiss, micaschists, and quartzites), which is part of the Dahomeyan formation. Foliation in the basement is north-south oriented, and the mean dip angle is $20^{\circ}$ east [Descloitres et al., 2011]. Geological features show marked spatial heterogeneities: highly clayey areas can be found within a few dozen meters of fresh rock and weathered sandy material [Descloitres et al., 2011; Hector et al., 2013].

At the country scale in Benin, soil variability is primarily determined by the main geological units and/or large morphostructural units. At a local scale, they are determined by factors that control the preservation or the transformation and erosion of an ancient lateritic mantle [Faure, 1977; Faure and Volkoff, 1998]. Faure and Volkoff [1998] describe two major features that may coexist locally: (1) polycyclic soils consisting of upper clay-poor horizons overlying a hard or soft ferricrete (hardpan) developed above a thick clayey mantle. The upper horizons are gravelly, with quartz and iron nodules that result from in situ accumulation. (2) Where the previous clayey mantle has been eroded down to the basement, soils are formed of saprolite, with some clayey weathering layers. Clay eluviation processes (i.e., clay removal from a soil layer) are highly pronounced and enhanced by lateral movement of water above the low-permeability clayey layers, resulting in potentially thick and coarse textured soil profiles. Two representative soil profiles (Figure 2) were extracted from station 18 and from a trench (Ta) dug $70 \mathrm{~m}$ south of the FG5 gravimeter site (Figure 1d). Figure 2a corresponds to the first class of polycyclic soils and is representative of the western part of the catchment (stations 18, 19, 20 and M). Topsoil is less than $0.5 \mathrm{~m}$ deep, the hardpan cover (sample shown in the top insert photo of Figure $2 \mathrm{a}$ ) is $1.5-2 \mathrm{~m}$ thick and the bottom of the underlying clayey horizon was not 


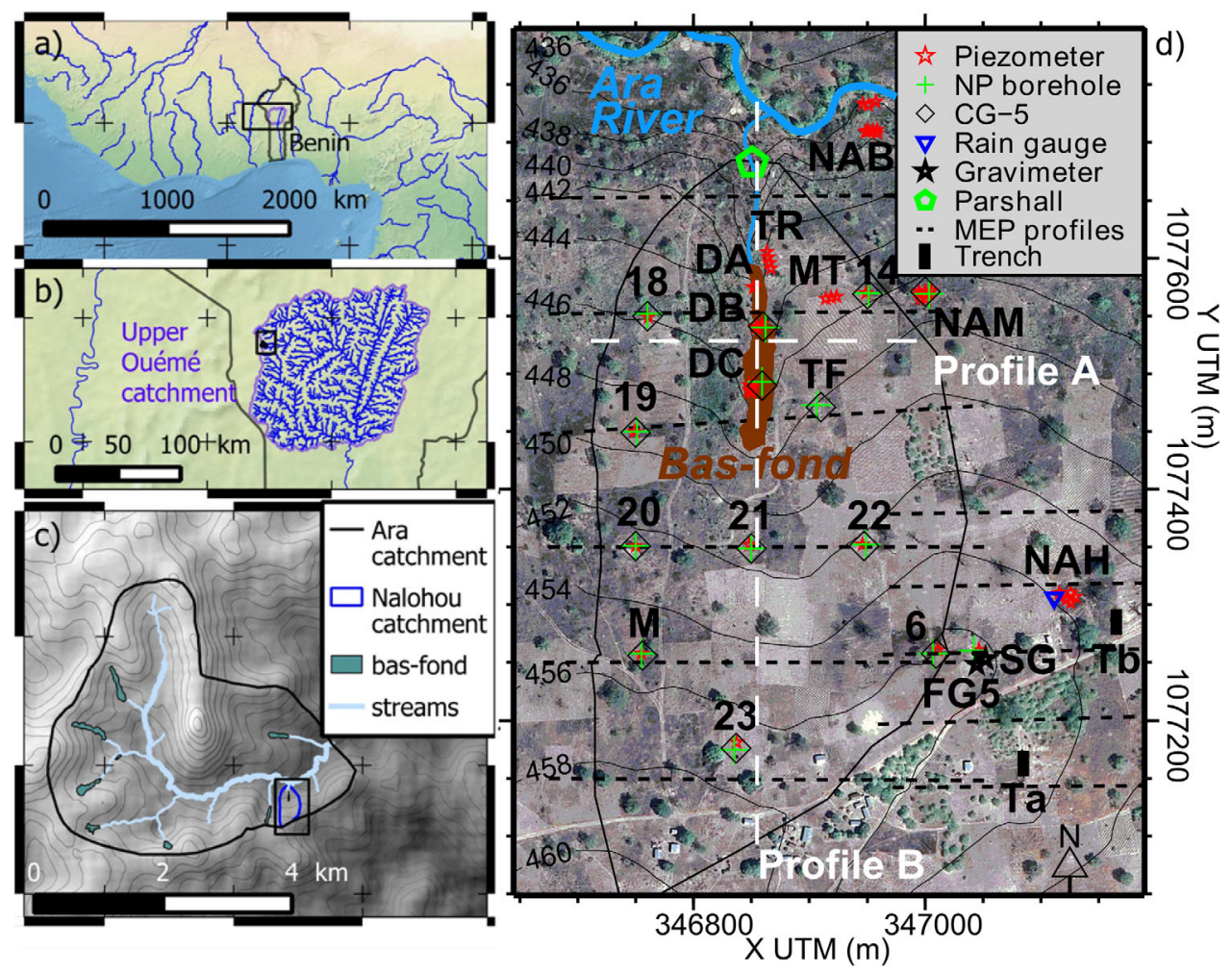

Figure 1. Study area. (a) Benin and upper Ouémé catchment location. (b) Upper Ouémé catchment and Ara catchment location. (c) Ara catchment with bas-fonds and Nalohou catchment locations. Topographic contour lines spacing is $5 \mathrm{~m}$. (d) Nalohou catchment, instruments (NP = neutron probe), MEP (multielectrode profiles), trenches, bas-fond, and conceptual model cross-section locations. Contour lines show land surface topography with $2 \mathrm{~m}$ spacing.

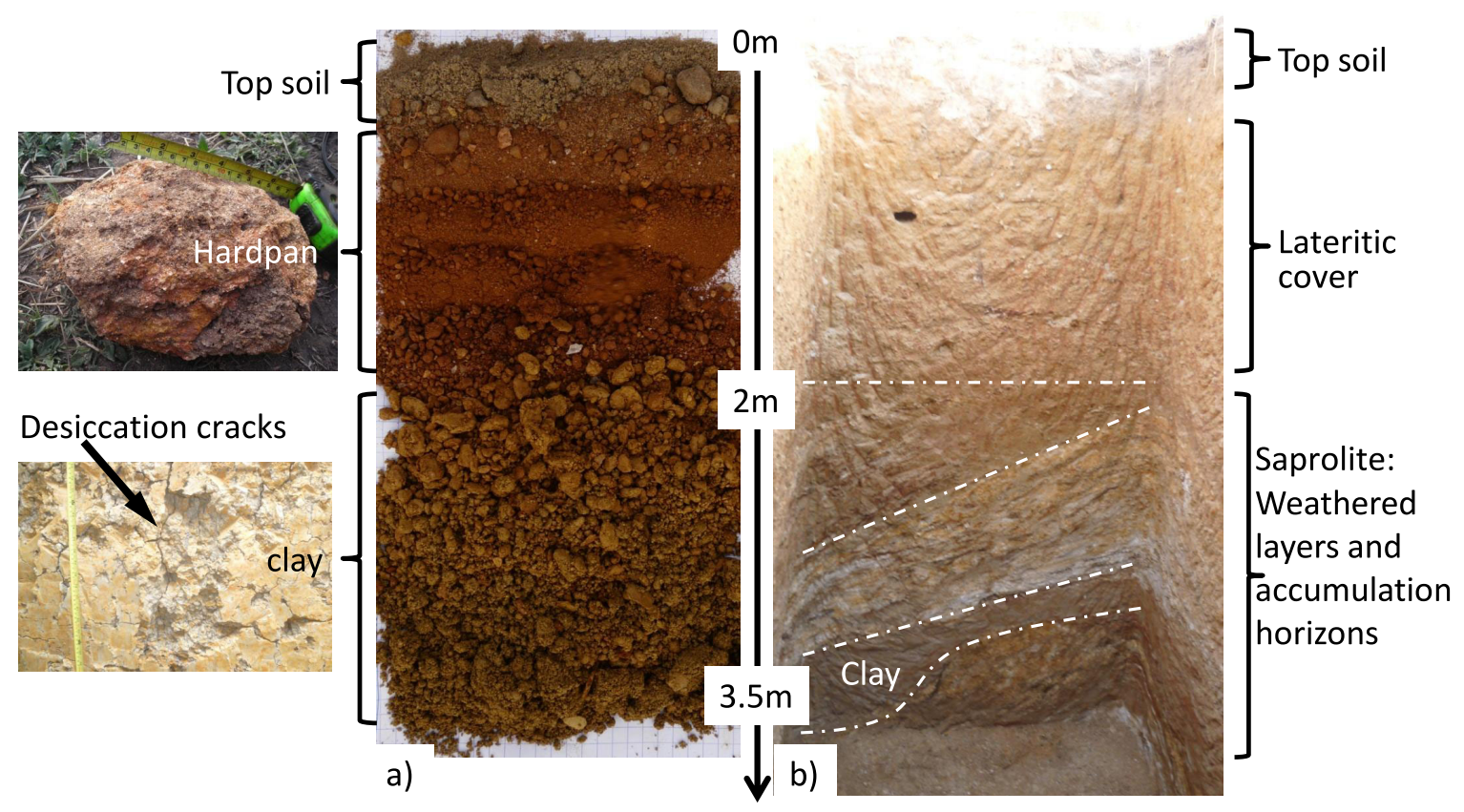

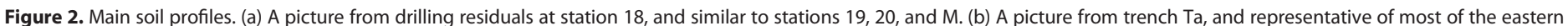
stations, and stations 22 and 23. Bas-fond soil profile is not shown here. Inserts are pictures from a hardpan sample and clayey wall from trench Tb, showing desiccation cracks after 1 day of exposure. 
reached by drilling. The bottom insert photo in Figure 2a shows a clayey wall from a trench (Tb, Figure 1d) dug in this horizon during the dry season, which exhibited desiccation cracks after 1 day of exposure. Figure $2 \mathrm{~b}$ corresponds to the second class and is representative of most of the eastern stations, and stations 22 and 23. The upper layer (about $1.5 \mathrm{~m}$ thick) of the saprolite is a rather homogeneous lateritic cover, while the lower saprolite is highly heterogeneous and extends down to the basement. Some combinations of these two distributions can also be found, such as station 21 , with a hardpan cover underlying saprolite material. A third soil feature is present within the bas-fonds. There, a sandy layer forms the upper part of the profile, underlain by a low-permeability clay accumulation horizon over hard rock or weathered layers [Raunet, 1985]. A similar soil structure, including bas-fonds, can be found in other Sudanian areas (e.g., Cameroon) [Brabant, 1991].

Land surface elevation ranges from 436 to $460 \mathrm{~m}$ asl, and topographic slopes are gentle (0-2\%) on average. Land use is governed by agricultural practices, with crops (maize, sorghum, manioc, and yam) and fallow rotations. Some specific trees (Parkia biglobosa, Vitellaria paradoxa, and Adansonia digitata) are kept for consumption and supplementary income purposes. Fallow fields are composed of trees (e.g., Isoberlinia doka) and herbaceous cover; the latter is usually burnt at the beginning of the dry season. The small bas-fond at the headwaters of the catchment may be used for small rice or yam plots. A small riparian forest (about $20 \mathrm{~m}$ wide) lies along the Ara River, downstream from the bas-fond.

Quick percolation of rainwater through the sandy top soil is favored by the presence of macropores from bioturbation [Giertz and Diekkrüger, 2003; Robert, 2012; Richard, 2014]. While there is no consensus on the relative permeability between fallow and cultivated areas [Giertz et al., 2005; Richard, 2014], both found in the Nalohou catchment, the high average permeability of top soils largely prevents Hortonian runoff. This is a common feature in Sudanian West Africa [e.g., Masiyandima et al., 2003].

The groundwater system is composed of permanent unconfined groundwater in the weathered mantle and by temporary perched groundwater (0-2 $\mathrm{m}$ deep) during the core of the rainy season (July-September) in the bas-fonds and in some places along the hillslopes. The permanent aquifer is fed by annual direct recharge. According to chemical signatures, the permanent groundwater does not seem to drain to rivers, unlike the seasonal perched groundwaters, which are the major contributor to annual streamflow [Séguis et al., $2011 \mathrm{~b}$ ]. Using hydrochemical data, these authors found a contribution of base flow to total streamflow from temporary perched groundwaters of $68 \%-88 \%$ on a larger catchment $\left(105 \mathrm{~km}^{2}\right)$ that includes the study area. Depletion of the permanent groundwater during the dry season is thought to be due to evapotranspiration processes, mainly driven by the downstream riparian zone which maintains permanent groundwater disconnection from the stream [Séguis et al., 2011b; Richard et al., 2013].

The rainfall regime follows the monsoon dynamics, and about $65 \%$ of annual precipitation occurs during the July-October period [Le Lay and Galle, 2005]. Mean annual precipitation was $1195 \mathrm{~mm} / \mathrm{yr}$ over the 1950-2004 period at the Djougou weather station, $8 \mathrm{~km}$ from the Nalohou site [Kamagate et al., 2007]. The two main discharge terms of the annual water budget are evapotranspiration (75\%-90\% of total precipitation) and streamflow (10\%-15\%). The residual term forms the interannual underground water storage variation [Kamagaté et al., 2007; Guyot et al., 2009; Descloitres et al., 2011; Séguis et al., 2011b]. Mean annual reference evapotranspiration [Allen et al., 1998] is $1393 \mathrm{~mm}$ over the 2002-2006 period at the Djougou weather station, with low seasonal variability between 3 and $4 \mathrm{~mm} \mathrm{~d}^{-1}$ in the wet season and up to 5$6 \mathrm{~mm} \mathrm{~d}^{-1}$ in the dry season [Séguis et al., 2011b]. During the wet season, once soils are wet enough, actual evapotranspiration is equal to reference evapotranspiration [Richard et al., 2013], with a constant evaporative fraction [Guyot et al., 2012; Mamadou et al., 2014]. No streamflow is observed during the dry season at the outlet of the Nalohou catchment, in the Ara River, or in the larger Donga (586 $\mathrm{km}^{2}$ ) basin. Intermittent streamflows lasting a few days are observed in the Ara River before the flow becomes permanent around July. Streamflow eventually stops at the end of the wet season, around November.

\section{Material and Methods}

\subsection{Hydrologic Data}

The Nalohou catchment has been equipped with hydrological instruments since 2003 within the AMMACATCH program (Figure 1d). Most of these stations have been coupled with concrete pillars for microgravity monitoring. Rainfall is monitored by a tipping-bucket rain gauge (Figure 1d). 


\section{QAGU Water Resources Research}

\begin{tabular}{|c|c|c|c|c|c|c|c|c|c|c|c|}
\hline Station & $\begin{array}{l}\text { Depth } \\
\text { NP }(m)\end{array}$ & $\begin{array}{c}\text { Depth } \\
\text { Observation } \\
\text { Wells }(\mathrm{m})\end{array}$ & $\begin{array}{c}\Delta \mathrm{h} \\
2011(\mathrm{~m})\end{array}$ & $\begin{array}{c}\Delta \mathrm{h} \\
2012(\mathrm{~m})\end{array}$ & $\begin{array}{l}\text { Mean } \\
\mathrm{h}(\mathrm{m})\end{array}$ & $\begin{array}{c}\text { WSC } \\
2011(\mathrm{~mm})\end{array}$ & $\begin{array}{c}\text { WSC } \\
2012(\mathrm{~mm})\end{array}$ & $\begin{array}{c}\text { Observation } \\
\text { Wells Setup } \\
\text { Year }\end{array}$ & $\begin{array}{c}\text { Depth } \\
\text { H2-H3 (m) }\end{array}$ & $\begin{array}{c}\text { Depth } \\
\text { Bedrock }(\mathrm{m})\end{array}$ & $\begin{array}{l}\text { Depth } \\
\text { Clay }(\mathrm{m})\end{array}$ \\
\hline 23 & 7.5 & 8 & $2.76 \pm 0.12$ & $3.58 \pm 0.07$ & 4.612 & $325 \pm 25$ & $360 \pm 30$ & 2011 & 1.5 & & \\
\hline FG5 & 7.5 & 10.6 & $1.8 \pm 0.13$ & 4.21 & 5.95 & $135 \pm 15$ & $245 \pm 5$ & 2009 & 2 & & \\
\hline 6 & 9 & 6.5 & $1.30 \pm 0.09$ & $3.08 \pm 0.02$ & 5.934 & $190 \pm 10$ & $230 \pm 10$ & 2011 & 2 & 4 & \\
\hline 21 & 7.5 & 6.5 & $2.54 \pm 0.13$ & $3.65 \pm 0.16$ & 3.406 & $150 \pm 10$ & $185 \pm 35$ & 2011 & 1.5 & 5.5 & \\
\hline 22 & 7.5 & 8.6 & $1.74 \pm 0.4$ & $3.18 \pm 0.14$ & 3.854 & $185 \pm 45$ & $200 \pm 30$ & 2011 & 1.5 & 5.5 & \\
\hline 20 & 2 & 3 & & & & 50 & 120 & 2011 & 2 & & 2 \\
\hline M & 2.5 & 7 & $2.92 \pm 0.09$ & $3.06 \pm 0.04$ & 4.154 & $85 \pm 5$ & $125 \pm 5$ & 2006 & 2 & & 2 \\
\hline 19 & 3.5 & 3.6 & & & & $100 \pm 10$ & $130 \pm 10$ & 2011 & 2 & & 2 \\
\hline 18 & 4.5 & 3.8 & & & & $130 \pm 10$ & $150 \pm 10$ & 2011 & 2 & & 2 \\
\hline TF & 5.5 & 8.5 & $1.36 \pm 0.11$ & $1.88 \pm 0.19$ & 2.942 & $159 \pm 17$ & $222 \pm 6$ & 2009 & 2 & & \\
\hline DC & 6 & $0.5 / 1 / 1 / 6 / 10$ & $2.59 \pm 0.21$ & $2.84 \pm 0.15$ & 4.914 & $285 \pm 25$ & $275 \pm 15$ & $2004 / 2011$ & 2 & 3.5 & \\
\hline DB & 9 & $0.5 / 1 / 1 / 9.1$ & $1.71 \pm 0.04$ & $3.78 \pm 0.12$ & 7.482 & 170 & $240 \pm 10$ & $2004 / 2011$ & 1.5 & 3 & \\
\hline DA & & $1.88 / 0.98$ & & & & & & 2004 & & & \\
\hline MT & & $02 / 10 / 20 / 20$ & $1.77 \pm 0.12$ & 1.82 & 4.165 & & & 2004 & & & \\
\hline TR & & $2 / 10 / 20 / 40$ & $1.73 \pm 0.06$ & 2.07 & 9.455 & & & 2004 & & & \\
\hline 14 & 7 & 8 & $2.68 \pm 0.01$ & $3.68 \pm 0.5$ & 3.876 & 180 & $240 \pm 10$ & 2011 & 2.5 & 2.5 & \\
\hline NAM & 6 & $2 / 10 / 10 / 10 / 20 / 20 / 20$ & $2.03 \pm 0.15$ & $2.37 \pm 0.12$ & 3.846 & $216.5 \pm 8.5$ & $276.5 \pm 4.5$ & 2004 & 2 & 3 & \\
\hline
\end{tabular}

${ }^{\mathrm{a}}$ Seasonal variations of water table $(\Delta \mathrm{h})$ and WSCs from NP for each year (2011 and 2012) are indicated. Values are averages of recharge and discharge periods and errors are deviations from this average. When available, depth of clay, bedrock, and the bottom of second horizon (depth $\mathrm{H} 2-\mathrm{H} 3$ ) are also indicated.

\subsubsection{Streamflow}

A Parshall flume was built in 2004 at the outlet of the bas-fond (Figure 1d) and recorded any level change above $10^{-3} \mathrm{~m}$, using a level probe (OTT Thalymedes). Water depth data from the probe were checked by comparing with manual observations every day during the flow period. For partitioning streamflow into direct runoff and base flow, a two-parameter recursive digital filtering approach [Eckhardt, 2005] was applied to the hydrograph. This filter was constructed under the assumption that the outflow from the aquifer is linearly proportional to its storage. It was chosen for its physical basis, agreement with other digital filters [Eckhardt, 2008] and because it produced results in accordance with annual base flow-to-streamflow ratios derived from geochemical observations over a larger area $\left(105 \mathrm{~km}^{2}\right)$ that included the study area [Séguis et al., $2011 \mathrm{~b}$ ].

\subsubsection{Water Table}

Observation wells were made of $63 \mathrm{~mm}$ diameter PVC casing with a 1-2 m long screen at the bottom, depending on whether it was a shallow or a deep station, respectively (Figure $1 \mathrm{~d}$ and Table 1). Observation wells at stations NAM, MT, and TR consist of at least three wells drilled 2, 10, and $20 \mathrm{~m}$ deep in 2003-2004. In 2004, the first observation wells in the bas-fond were drilled 1-2 $\mathrm{m}$ deep to document the shallow and seasonal perched aquifer (DA, DB, and DC). This small network was later expanded to the whole catchment. Water-level measurements were made manually at each station, every 2 days for stations in the bas-fond and the NAM, MT, and TR stations, and weekly for other stations. Some stations in the bas-fond and the station close to the FG5 were equipped with total pressure transducers (Schlumberger Diver or Solinst Levellogger) compensated with a barometric pressure transducer to further check the manual readings.

\subsubsection{Water Storage Changes}

WSCs are monitored weekly using a NP (Campbell Pacific Nuclear Model 503DR) within PVC access tubes. First access tubes were installed in 2009 following the FG5 absolute gravity measurements (stations NAM, TF, and FG5). In 2011, more access tubes were installed, to be colocated with microgravity stations for all other stations (Figure 1d and Table 1). When possible, holes were drilled more than $1 \mathrm{~m}$ below the permanent water table, before the start of the rainy season when the water table was low. Measurements were made at depths of $0.15,0.3$, and $0.5 \mathrm{~m}$, then at $0.25 \mathrm{~m}$ intervals down to $2 \mathrm{~m}$, then at $0.5 \mathrm{~m}$ intervals to the bottom of each access tube.

Previous work calibrated NP measurements for three soil classes-soil, laterite, and alterite [Hector et al., 2013] — for a single site. Two additional soil classes, clay and bedrock, were identified in access holes across the study area. Soil moisture calibrations for these additional soil types are described in Appendix A.

\subsection{Hybrid Gravimetry}

Relative spring microgravimeters measure differences in gravity between stations while other instruments such as SG or AG measure changes at a specific site. Hybrid gravimetry is the joint use of gravity surveys using relative 


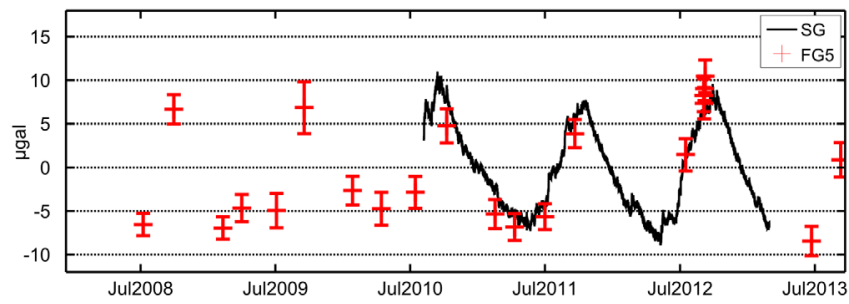

Figure 3. Gravity residuals of the superconducting gravimeter (SG) and the absolute gravimeter (FG5). microgravimeters and monitoring of temporal changes at a base station, using an SG and/or AG [Pool et al., 2000; Okubo et al., 2002; Pool and Anderson, 2008; Sugihara and Ishido, 2008]. In this study, we used an SG from GWR to monitor gravity changes at the base station and a Scintrex CG-5 relative gravimeter for the microgravity network.

\subsubsection{Gravity Monitoring at the Base Station}

A superconducting gravimeter, the SG-060, was installed as part of the Gravity and Hydrology in Africa (GHYRAF) project [Hinderer et al., 2009] and recorded gravity changes with a high accuracy $(\approx 0.1 \mu \mathrm{Gal})$ since July 2010. In addition, absolute gravity has been measured using a FG5 at a 3 month sampling rate since July 2008 [Hinderer et al., 2009, 2012; Hector et al., 2013; Hinderer et al., 2014a; Hector et al., 2014]. Instrument locations are shown in Figure 1d. A detailed description of data processing, sensitivity analysis, and the footprint area of the gravimeters can be found in Hector et al. [2014]. The main results are summarized herein and gravity residuals (after corrections of tides, ocean loading, polar motion, and atmospheric effects) are shown in Figure 3.

The water admittance value (i.e., the ratio between gravity changes and a uniform layer of water spread on

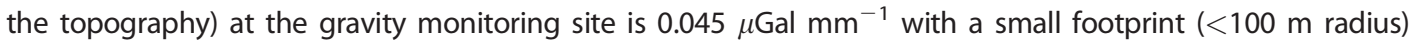
[Hector et al., 2014]. This is close to the Bouguer value, $0.042 \mu \mathrm{Gal} \mathrm{mm}{ }^{-1}$, for the theoretical "flat terrain" case. Although the relationship between WSCs and gravity changes may not be straightforward because of spatial heterogeneities of soil properties and the shelter masking effect [e.g., Deville et al., 2012], it is reasonable to assume a linear relationship as a first-order approximation for long-term processes ( $>1$ week). The impervious shelter prevents both the infiltration of precipitation into the subsurface directly below the shelter and evapotranspiration to the atmosphere and also modifies infiltration processes around the building. This effect prevents to use the gravity measurements for retrieving the hydrological fluxes of interest (i.e., evapotranspiration and infiltration) from fast WSCs occurring close to the surface. Gravity residuals are still affected by errors in the atmospheric corrections at short time scales (less than a few hours) and diurnal and semidiurnal bands, but these corrections are valid for atmospheric effects occurring over longer periods.

The direct comparison of the gravity effect calculated from local hydrological data (i.e., NP and groundwater levels) with observed SG data shows substantial discrepancies: (1) in the signal amplitude, attributed to an excessively low calibration value for the NP and (2) in the highly contrasted hydrological years 2011 (949 mm precipitation) and 2012 (1422 mm), where seasonal gravity changes (both seen by the AG and SG) exhibit few differences from one year to another as opposed to local hydrological monitoring (NP, water table), which is much more variable. This latter point has not been explained so far.

\subsubsection{Microgravity Network}

Time-lapse microgravity studies for hydrology usually concern amplitudes ranging from a few up to hundreds of microgals ( $1 \mu \mathrm{Gal} \approx 24 \mathrm{~mm}$ of homogeneous one-dimensional WSC) and spatial coverage of a few meters up to tens of kilometers in various environmental settings. Depending on these conditions, specific survey designs have to be defined, in particular the number of stations, locations and reoccupations, measurement times, and loop geometry (loops are needed for instrumental drift control). All these considerations impact data accuracy. For instance, instrument transportation and hence the distance between stations is known to affect relative-gravity survey accuracy [McClymont et al., 2012; Masson et al., 2012; Pfeffer et al., 2013]. Gettings et al. [2008] reported on a number of studies using many reoccupations and/or several gravimeters to constrain drift and detect nonlinear drifts and tares. Requirements and recommendations for high-quality survey designs can be found in Seigel et al. [1995]. In this study, an appropriate survey design was required to detect the small spatial variations of WSCs. Survey design details, including station construction, loop geometries, and measurement protocol, together with data processing steps can be found in Appendix B. The microgravity network is composed of 13 stations $(18,19,20,21,22,23, M, 6$, TF, 14, NAM, DA, DB, Figure 1d) plus a base station located on the FG5 pier, about $7 \mathrm{~m}$ southwest of the SG pier within a shelter that is similar in size to the SG shelter. 
Residual microgravity data are obtained after correction of temporal effects other than local hydrology (see Appendix B). Before interpreting these residuals in terms of local hydrology, a sensitivity analysis was undertaken to explore other potential local effects on gravity, including temporal effects such as vertical motion (displacement of the gravimeter in the earth gravity field), erosion (mass removal), and vegetation (seasonal mass variations), or static effects such as topography, shelter masking, or station construction [Van Camp et al., 2006; Kroner and Jahr, 2006; Hasan et al., 2006; Meurers et al., 2007; Creutzfeldt et al., 2008; Masson et al., 2012; Deville et al., 2012; Hector et al., 2014]. For the SG and FG5 base station, one may refer to studies conducted by Hector et al. [2013, 2014]. Concerning the microgravity network, a thorough sensitivity analysis can be found in Appendix B, the main results of which are summarized hereafter:

1. Leveling surveys show no gravity changes higher than $4 \mu \mathrm{Gal}$ should be expected from the vertical motion of the stations, and it is likely that the effect is actually much less. More specifically, it seems that the western stations $(18,19,20$, and $M)$ show the greatest sinking motion, which would lead to increasing gravity in time.

2. Based on the literature from nearby studies and field observations, the erosion effect is likely negligible $(<0.01 \mu \mathrm{Gal} / \mathrm{yr}$ ) in the time span of the present study ( $<3$ years).

3. No effect from the seasonal vegetation cycle should be expected above the CG5 resolution ( $1 \mu \mathrm{Gal}$ ), based on local biomass measurements.

4. All stations out of the bas-fond have water admittances between 0.04 and $0.044 \mu \mathrm{Gal} \mathrm{mm}^{-1}$ (gravity effect of a layer of water spread on the topography; see Figure B1 in Appendix B), suggesting a small topographic role (departing no more than $5 \%$ from flat terrain, which is the Bouguer value of $0.042 \mu \mathrm{Gal}$ $\mathrm{mm}^{-1}$ ). Here topographic effect is referred to as the direct effect of a water layer on gravity, which originates from terrain elevation variations in space around a gravity station on which the water layer is distributed (i.e., the spatial distribution of WSC is assumed to mimic topography). The effect of topography on water redistribution is not taken into account here. If WSCs are assumed to be uniform within the sensitivity zone around a gravimeter, gravity changes can be directly converted to WSC. Negative admittances can be found in the valley bottom close to the outlet where topography is marked by the drain incision. If gravity measurements were taken there, gravity inversion for WSC retrieval would certainly be less intuitive due to topographic effects. Further, because the topographic effect is small and WSCs occur in the first few meters below the surface, all stations have a small footprint for WSC retrieval less than $100 \mathrm{~m}$. Only stations located in the bas-fond exhibit specific behaviors in the near field, because of this small topographic depression. At these bas-fond stations, the calculated gravity effect at shallow depths decreases for a certain radius increase, at which point this radius starts to include the bas-fond banks located at higher elevations than the bas-fond stations. This also impacts water admittance values, which range from 0.034 to $0.038 \mu \mathrm{Gal} \mathrm{m^{-1 }}$, upstream of the bas-fond, but still in the thalweg.

5. No WSCs can be expected from inside the concrete pillar. The maximum effect from the pillar's masking role is about $10 \%$ of the Bouguer plate $\left(4 \times 10^{-3} \mu \mathrm{Gal} \mathrm{mm}{ }^{-1}\right)$ at $0.1 \mathrm{~m}$ depth and less than $2 \%\left(7 \times 10^{-4}\right.$ $\mu \mathrm{Gal} \mathrm{mm}^{-1}$ ) at $1 \mathrm{~m}$ depth, which is negligible in terms of CG5 accuracy.

Microgravity data are arranged by survey days, which produce what is known as "simple differences" among stations: because of the instrumental drift, microgravity measurements at different stations have to be undertaken in a loop scheme, with one or several repetitions of the base station to constrain the drift. Therefore, spatial gravity differences between each station and the base station are obtained. These values are in the milligal range and result from height differences between stations, topographic effects and spatial distribution of rock densities, and other static effects. When the difference between two surveys is calculated (double difference), all static effects cancel out and what remain are the time changes of gravity differences with respect to the base station. Then gravity changes observed by the SG between survey dates are added to the base station, and therefore added to the double difference at each station, forming the hybrid gravity data set.

\subsection{Hydrostratigraphic Mapping}

In a previous study, apparent resistivity mapping and magnetic resonance soundings (MRS) were undertaken to delineate structures and provide estimates of storage parameters in the surroundings of the gravity base station [Descloitres et al., 2011]. In addition, 11 west-east multielectrode profiles (MEPs) were made in the area: six over the small watershed and five around the gravity base station (Figure 1d). The MEP is an appropriate technique for identifying subsurface electrical resistivity and delineating weathered rock-fresh 
basement interfaces in tropical weathered crystalline basement environments, as well as for identifying low resistivity clayey areas [Beauvais et al., 1999; Seaton and Burbey, 2002; Braun et al., 2009]. Wenner and dipole-dipole arrays were both used because these arrays provide an adequate description of highly variable variations of subsurface resistivity encountered in weathered hard rock tropical aquifers [Descloitres et al., 2008]. Data sets were interpreted using the DC2DInvRes interpretation software [Günther, 2004]. The resistivity results were used together with NP time series, drill log cuttings, MRS, and apparent resistivity mapping to build a simplified structural 3-D model for the small watershed subsurface.

\subsection{Spatial and Temporal Variability of Water Storage Changes}

Spatial and temporal variability can be assessed for a given stationary field using EOFs. This statistical tool has been extensively used in atmospheric sciences [see e.g., Preisendorfer and Mobley, 1988; Jackson, 2004; Jolliffe, 2005; Hannachi et al., 2007] for the identification of the spatiotemporal features present in atmospheric data. In the hydrology field, Verhoest et al. [1998] identified the spatiotemporal patterns of soil moisture and found that it was consistent with the rainfall-runoff dynamics of the catchment. A few studies tried to link these surface soil moisture patterns derived from EOF analysis with relevant features (topography, soil properties, and land use/land cover) with different conclusions depending on study locations, the main hydrological processes, the period considered (wet, dry, and intermediate) and also on the scales (both temporal and spatial) at which the method was applied [Kim and Barros, 2002; Yoo and Kim, 2004; Jawson and Niemann, 2006; Perry and Niemann, 2007]. In the field of gravimetry, EOFs have been applied over Europe to compare ground-based superconducting gravimeter data sets, GRACE solutions, and outputs from global hydrological models, mainly for validating GRACE solutions [Crossley et al., 2004; Neumeyer et al., 2008; Abe et al., 2012; Crossley et al., 2012].

EOFs can be seen as the particular case of principal component analysis applied to the time series of a spatial field. It is a powerful tool to analyze the variability of a single scalar variable. The method produces spatial patterns of variability (in terms of variance), their associated time variation together with a measure of the weight (importance) of each pattern (in terms of explained variance). The method for constructing EOFs is rather simple: data are organized as a [t,n] matrix (S-mode analysis), where $t$ is time series length (sampled at the same dates) and $\mathrm{n}$ the number of stations. Singular value decomposition is then applied to the covariance matrix of this data set. This results in $n$ eigenvectors of length $n$ (called the EOFs, or modes), which are the spatial patterns of variability, and $n$ eigenvalues, which give the variance explained by each mode. Associated time series (also called expansion coefficients) for each EOF are found by projecting the initial data set on the EOFs. Therefore, this method identifies the spatial organization of the common variance features.

The variance explained by each mode is its eigenvalue divided by the sum of all eigenvalues. The signal can be reconstructed back by summing each projection (multiplication) of a time series (expansion coefficient) on its associated spatial pattern (EOF).

In this paper, initial data sets are first detrended and zero averaged. This makes it possible to focus only on the seasonal and subseasonal components. Also, the expansion coefficients are normalized, and associated EOFs corrected accordingly, to favor simultaneous reading of these two products. EOFs were applied to hybrid gravity data and NP-derived WSCs.

\section{Results}

\subsection{Precipitation Records}

Precipitation records from years 2009 to 2012 showed the strong seasonality that results from the WestAfrican monsoon dynamics. They exhibited different intraseasonal patterns from one year to another (Figure 4) and a marked interannual variability of cumulated values (from $949 \mathrm{~mm}$ in 2011 to $1528 \mathrm{~mm}$ in 2010; Figure 5). These temporal patterns are typical of the area [Le Lay and Galle, 2005].

\subsection{Streamflow Analysis}

Streamflow was seasonal (Figure 4): intermittent streamflow lasting for a few days was observed between April and July, following precipitation patterns, before permanent streamflow takes place around July (the seasonal flow period is shown by vertical dashed lines in Figure 4). During the wet season, if precipitation is not sufficient, streamflow may temporarily cease (as in 2011). The streamflow period is over around the end of October. 


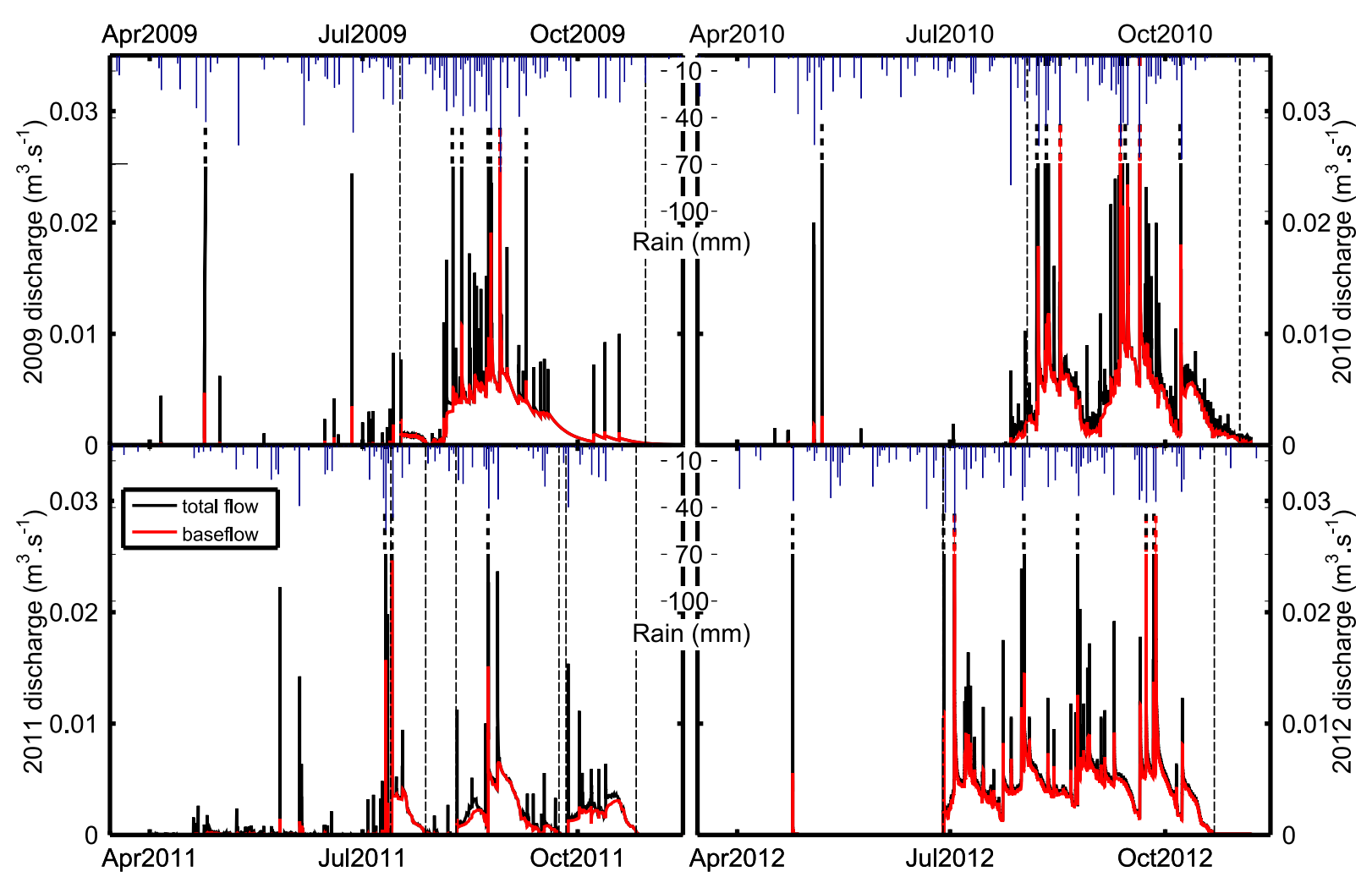

Figure 4. Streamflow decomposition for 2009-2012 and daily precipitation. Dashed lines are start/end dates of seasonal streamflow. Solid lines terminated by dashed lines indicate a higher discharge, not shown in this figure.

Base flow separation is shown in Figures 4 and 5 as annual amounts relative to precipitation. For clarity, Figure 4 only shows the lower part of the streamflow time series, and peak values (as marked by vertical dashed lines) are not visible. Some base flow peaks are visible, but they should not be interpreted as actual peaks, in that they never exceed $15 \%$ of the total streamflow peaks for the highest events (marked by red vertical dashed lines), it is a scaling artifact. Base flow is the major component of streamflow, with $73 \%-$ $87 \%$ of total flow depending on the year. For instance, for a $38 \%$ decrease in yearly cumulative precipitation between $2010(1528 \mathrm{~mm}$ ) and $2011(949 \mathrm{~mm})$, the surface runoff decrease was 27\% and base flow decrease was 56\%. For a 33\% increase in precipitation between 2011 and 2012 (1422 mm), the surface runoff increase was $13 \%$ and base flow increase was $190 \%$. While the rainfall-base flow relationship is likely nonlin-

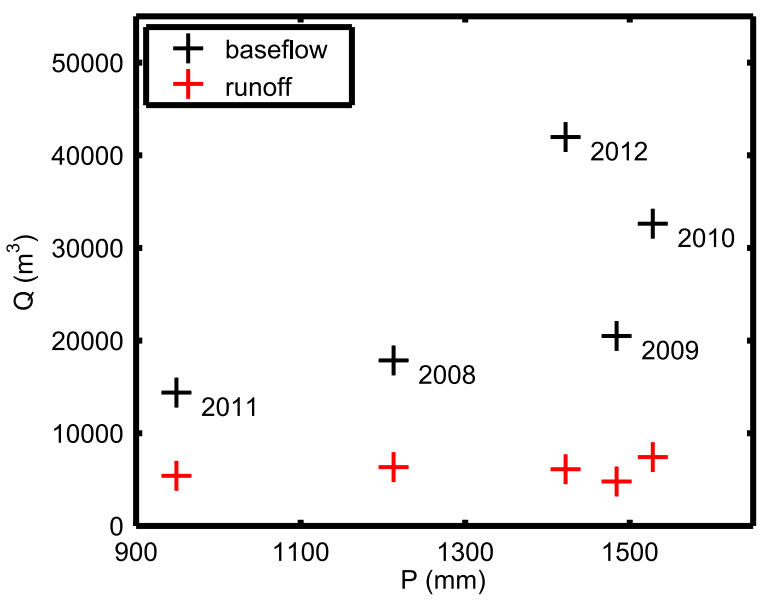

Figure 5. Yearly precipitation $(P)$-discharge $(Q)$ relationships for base flow and runoff discharge components. ear, it is clear that much of the precipitation variation propagates through the subsurface.

\subsection{Water Table Variation Analysis}

Water-level variations in the permanent water table (FG5, TRdeep, NAM, 6, DBdeep, DCdeep, TF, 14, 18, 19, 20, 21, 22, 23, M, and MT) are shown in Figure 6 , together with water levels in shallow wells sampling the perched aquifer in the bas-fond (DA, DB, and DC) and surroundings (TR). Water levels from other observation wells that are colocated with each station (Figure 1d and Table 1) were usually similar to the time series shown in Figure 6. Some shallow wells (not shown) located about $100 \mathrm{~m}$ east of the catchment showed a temporary perched water level above $2 \mathrm{~m}$ in depth at the core of the rainy 


\section{QAGU Water Resources Research}

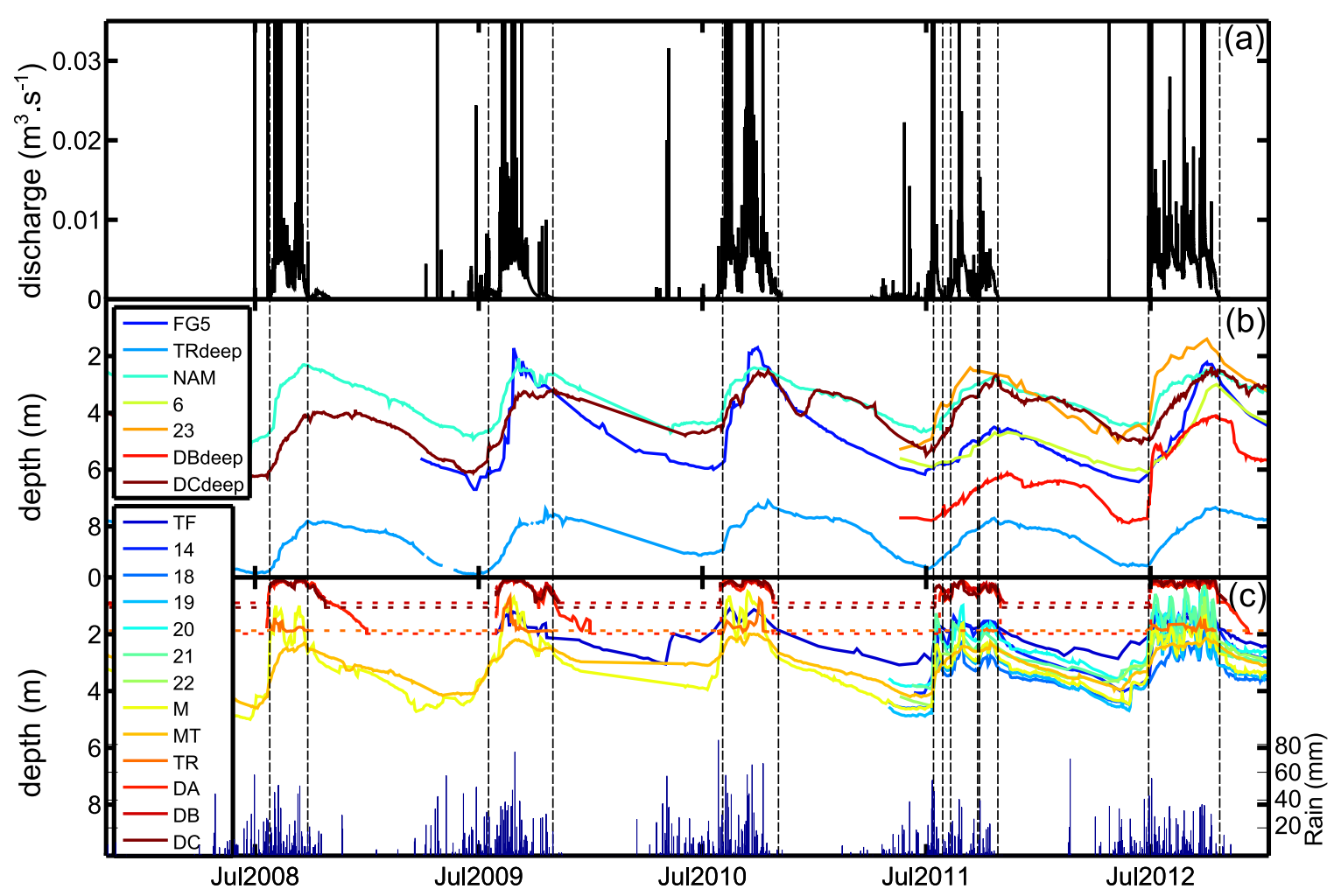

Figure 6. Streamflow, water table, and precipitation for 2008-2012. (a) Streamflow. (b) Water table in wells that show no capping. (c) Water table in wells showing a capping behavior and daily precipitation. Vertical dashed lines represent starting dates and ending dates for the seasonal flow period. Horizontal dashed lines represent dry wells depths.

season [Séguis et al., 2011b; Richard et al., 2013]. Figure 6a shows the streamflow record. Vertical dashed lines define seasonal flow periods (when streamflow is not interrupted). Water-level variations are classified into two groups (Figures $6 \mathrm{~b}$ and $6 \mathrm{c}$ ) based on capping behavior. Capping was generally characterized by a sharp increase in the water table, a plateau with some high-frequency variations (related to precipitation events) during the flow period, with a short and sharp decrease followed by a slower recession period at the end of the flow period (Figure $6 \mathrm{c}$ ). This could be explained by an activation of lateral preferential flow network with a strong increase in the apparent hydraulic conductivity [Fannin et al., 2000; Tromp-van Meerveld and McDonnell, 2006; Anderson et al., 2010]. This phenomenon was observed in western observation wells (e.g., 18, 19, 20, and M) and in observation wells immediately upstream and surrounding the bas-fond (e.g., TF, MT, 21, and 22). All these observation wells sample the permanent water table. In shallow bas-fond observation wells (DA, DB, and $D C$ ), which sample the perched aquifer, high-frequency variations on the capping shape are likely due to short-duration saturation-excess overland flow. Stations with capping showed small differences in highly contrasted years (e.g., 2011 with $949 \mathrm{~mm}$ of rain and 2012 with $1422 \mathrm{~mm}$ ). Shallow wells (DA, DB, DC, and TR) were dry during the dry season, as exhibited by the flat horizontal dashed line of their time series (Figure $6 c$ ). Near the upper margins of the watershed and within the permanent aquifer below the bas-fond, observation wells generally showed a deeper water table, with a longer increase period, greater amplitude and no capping (Figure 6b). There is usually a peak when water table reaches its minimum value, late during the flow period. In these wells, infiltrated water takes a longer time to percolate downward through the unsaturated zone. They also tended to show a substantial difference in amplitude in contrasted years (Table 1).

\subsection{Water Storage Change Analysis}

WSCs obtained from NP measurements are shown in Figure 7. Stations in the bas-fond (DB and DC) sample the whole vertical column where WSCs occur (the shallow temporarily perched aquifer and the permanent aquifer). Station 20 is too shallow ( $2 \mathrm{~m}$ deep) to capture all WSCs. When the water table is deeper than $2 \mathrm{~m}$, NP measurements at station 20 underestimate the WSCs of the whole column, although the dense clay layer (which prevented a deeper NP access tube from being installed) below $2 \mathrm{~m}$ is not likely to be subject 


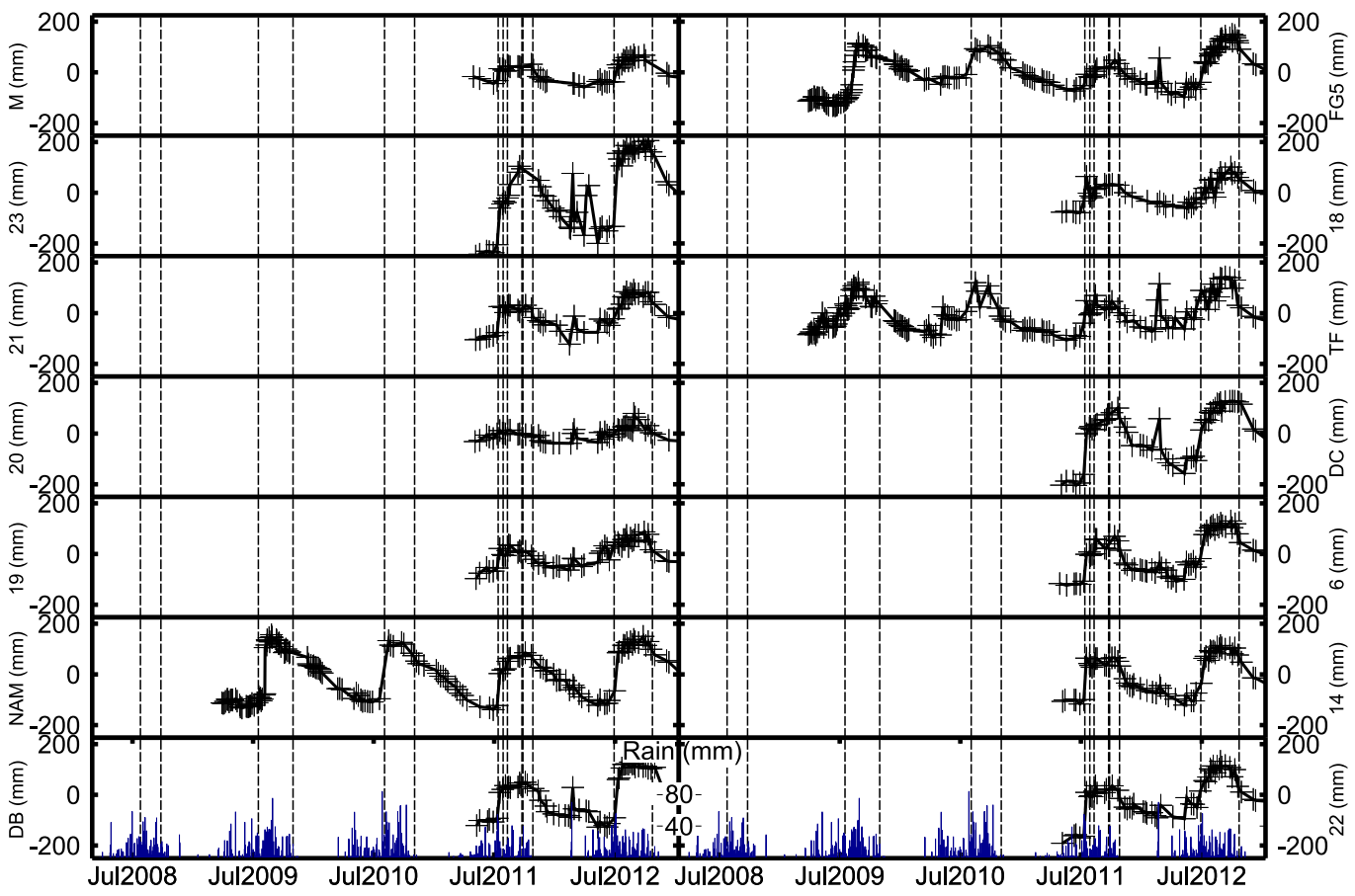

Figure 7. WSC from neutron probe (NP) and daily precipitation.

to high WSCs due to high retention capabilities. Stations from the west bank of the bas-fond (stations 18, 19, 20, and M) show the lowest seasonal amplitude (Table 1).

In a more recent work, Hector et al. [2014] noted significant discrepancies in amplitudes between WSCs deduced from SG and FG5 monitoring, and NP. This may be due to the sampling process: drying of drill cuttings could occur during excavation, resulting in calibration parameters that are too low, and hence underestimation of WSCs [Hector, 2014]. Therefore, this study mostly focuses on WSC behaviors, rather than absolute amplitudes.

\subsection{Hydrostratigraphic Mapping}

MEP cross sections showed a quite similar pattern across the catchment with low resistivity, clayey areas in the western part, and alternating weathered material in the eastern part. A typical example is shown in Figure 8a. An upper layer can be seen with a consistent depth (about $2 \mathrm{~m}$ ) in all profiles, corresponding to a hardpan unit on the western part of the catchment and to a lateritic cover in the east. Basement topography shows spatial variations, and zones with a higher basement elevation are overlain by a rather resistive material, which could correspond to less clayey and/or less weathered material than the surrounding parts.

Figure $8 \mathrm{~b}$ shows the results of hydrostratigraphic mapping. The color darkness of the units follows our conception of relative permeability between units: darker colors mean less permeable material. Based on drill log analysis (see interface depths in Table 1), NP-derived moisture maps and MEP, three layers were defined.

1. Layer H1 (not shown) ranges from the surface to $0.5 \mathrm{~m}$ deep and is composed of shallow soil, whose spatial distribution is not assessed in the present study.

2. Layer H2 (Figure 8b, left) is composed of three major units: (1) hardpan, mostly present in the western part of the catchment (some outcrops have also been identified), which typically consists of material shown in the drill logs cuttings in Figure 2a. This is a typical hardpan with macropores and poor matrix storage capacity with possible high permeability if macropores are connected. (2) Lateritic cover, of a rather reddish color, and higher clay content than the hardpan. (3) Bas-fond with typical sandy soil features. The mean depth range of this layer is $0.5-2 \mathrm{~m}$, although some deviations were observed locally (see Table 1). 
3. Layer H3 (Figure 8b, right), which extends from $2 \mathrm{~m}$ deep down to the basement, exhibits marked variations with a major clay unit in the western part of the catchment, and in some smaller areas around the gravity base station. This clay is the same as in Figure 2a, and a trench was dug slightly out of the study area in this unit (trench Tb, Figure 1d). In the dry season (March), $2 \mathrm{~m}$ deep clay showed a high water content, and after 1 day of exposure showed marked desiccation cracks. Furthermore, many drillings in this western clayey area were often unable to dig deeper than $1 \mathrm{~m}$ after clay was found, because of the much softer material, preventing the drill from working properly. This material is expected to have low permeability. After the clayey areas, saprolites showed the highest average NP water content and a high weathering stage based on drill cuttings. Within these saprolites, clayey zones were found. This unit had a high retention capacity. A typical example is presented in the excavated trench (Ta, Figure 1d) illustrated in Figure 2b. A less weathered material, here called fissured basement, showed an underlying basement topography closer to the surface than in other parts of the catchment, a lower NP water content than in the saprolites and a low weathering stage. The name is given after Lachassagne et al. [2011] who show that the unit has a significant secondary (fissure) permeability which originates from weathering processes. Drill cuttings showed unweathered material in sublayers within this layer. Based on the weathered state and lower retention capacity, this material is expected to be more permeable than the saprolites and clays in layer H3, if fissures are well connected. Saprolites are usually associated with less resistive materials than fissured basement. The depth of layer $\mathrm{H} 3$ varied with the basement topography, found between 7 and $22 \mathrm{~m}$.

The basement is not investigated in this study. We define the basement as the highly resistive material observed by MEP, and the apparently fresh rock from drill cuttings. It is assumed to have a very low permeability, although we have no direct evidence that it is not a transition zone (e.g., an extension of the fissured layer).

\subsection{Hybrid Gravity Data Analysis}

Seventy relative-gravity surveys were conducted between July 2011 and September 2013, covering three wet seasons with frequent measurements (approximately every 4-5 days), and two dry seasons with less frequent measurements (approximately every month). With more than 2100 station reoccupations lasting 10-30 min each, this is one of the densest time-lapse microgravity campaigns ever conducted, requiring more than $500 \mathrm{~h}$ of field work by two or three operators.

The gravimeter was hand carried between stations using a carriage to minimize mechanical shocks (Figure 9a). Mean standard deviations increase with distance to the base station (FG5) (Figure 9b). These averages are based on the 70 surveys, with approximately two repetitions per station for each survey (see Appendix $B$ for further details). The first thing to be noted is the high accuracy obtained, with low standard deviations, better than $2.5 \mu \mathrm{Gal}$. In addition, the clear relationship with the distance to the base station is notable, which contributes to explaining the low standard deviations obtained in such a small network.

Microgravity time series are presented as the change in gravity relative to the base station and to the first survey (Figure 10). The error bars are therefore the square root of the quadratic sum of the standard deviations of the first survey and subsequent surveys (those for which average values are shown on Figure 9b). SG data are limited to the 2010-2012 period, because of as yet unresolved acquisition problems. Hybrid gravity time series (not shown) were then derived by adding gravity changes observed by the SG (SG residuals, Figure 3), between survey dates to each station. They are the input data for the EOF analysis.

\subsection{EOF Analysis}

EOF analyses on both the hybrid gravity data set and the NP-derived WSCs were conducted (Figure 11). Figures $11 \mathrm{a}$ and $11 \mathrm{~b}$ are, respectively, the EOFs of the first mode for gravity changes and NP-derived WSCs. All maps are products of interpolations using cubic splines. Figure $11 \mathrm{c}$ is the cumulated variance explained by each mode for each data set. Figure 11d is the associated normalized mode 1 time series (ECs) for NPderived WSCs and gravity changes.

For both data sets, the first mode explains much of the variance in the data (79\% for gravity changes, and $90 \%$ for WSCs, Figure 11c). This means that in terms of variance, the signal can be reconstructed up to $79 \%$ for gravity and up to $90 \%$ for WSCs, by matrix multiplication of the EOF (spatial, Figures 11a and 11b) and ECs (time series, Figure 11d) of mode 1. The analysis period covers the time span sampled by the SG. The 2013 CG5 data were not used because acquisition problems in the SG prevented the hybrid approach. The 

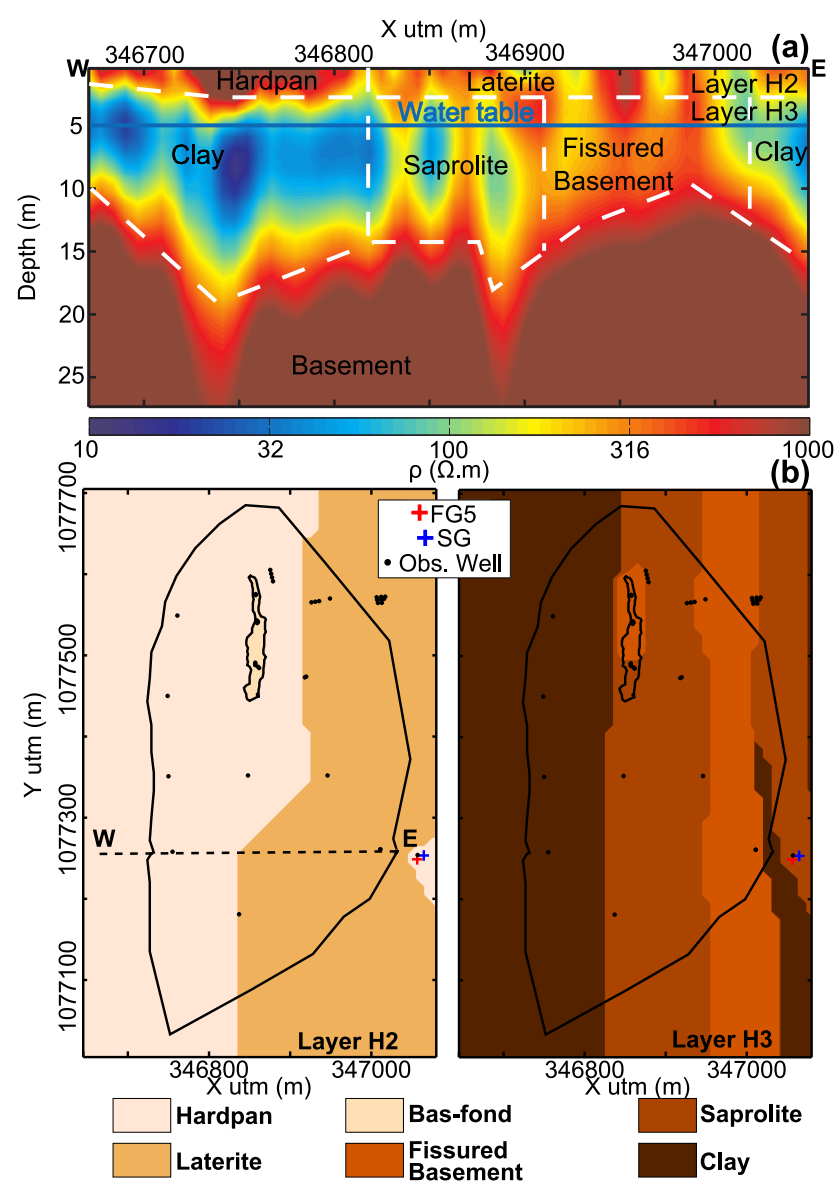

Figure 8. Structural mapping. (a) Typical interpretation of a MEP profile (profiles A and B). Approximate water table location is shown based on stations $M, 23$, and 6 at the MEP acquisition period (i.e., dry season). (b) Layer H2 (left) (0.5-2 m) and layer H3 (right) ( $2 \mathrm{~m}$ to basement) with location of profiles $A$ and $B$. Color gradient follows permeability: the darker the color, the less permeable the unit.

temporal aspect (ECs, Figure 11d) of mode 1 for all data sets shows that it is the seasonal signal that dominates the variance. Mode 1 of the EOFs therefore represents the spatial distribution of variations in this seasonal behavior. Seasonal amplitudes ranged from 12 to $22 \mu \mathrm{Gal}$ (twice the EOF range, because the associated EC has an amplitude of 2; Figure 11d) for the gravity signal, and from 80 to $320 \mathrm{~mm}$ for the NPderived WSC signal.
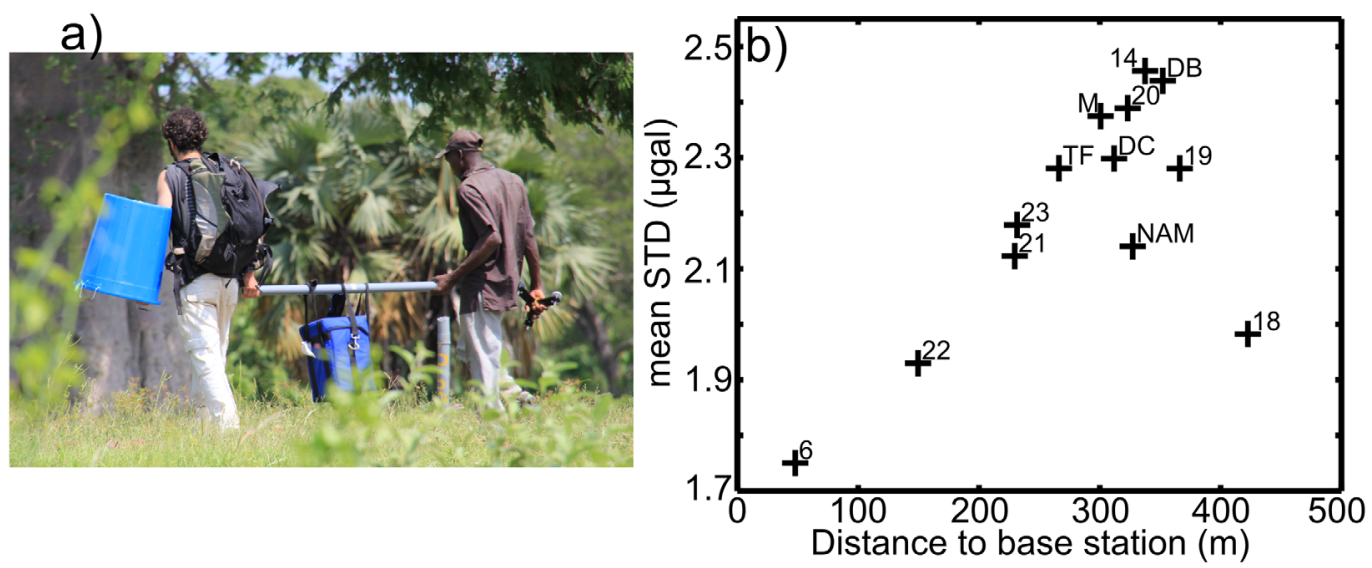

Figure 9. (a) CG5 transportation and (b) mean standard deviations of single differences at each station as a function of the distance to the base station. 


\section{QAGU Water Resources Research}
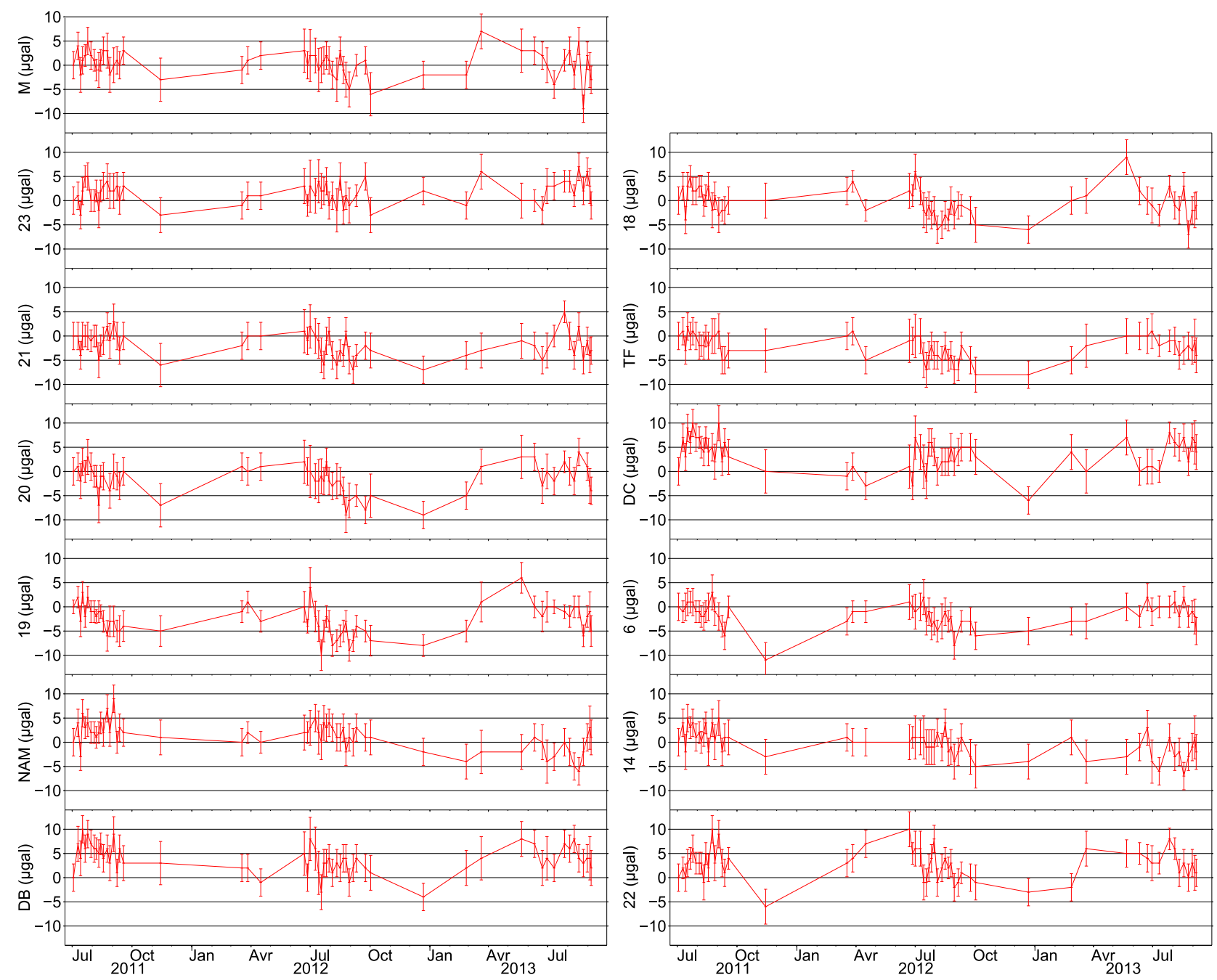

Figure 10. CG5 double differences with respect to the first survey.

\section{Discussion}

In the Nalohou catchment, base flow is the main component of streamflow, in accordance with studies at larger scales in the area [Giertz et al., 2006; Séguis et al., 2011b]. Base flow originates from the bas-fond, which is saturated during the seasonal flow period, as shown by observation wells (DA, DB, and DC) sampling the shallow perched aquifer (Figure 6). To track base flow generation processes and contributive areas, information on underground water distribution and lithological units has been gathered across the catchment and is discussed in this section which leads to a conceptual model for the catchment hydrology.

\subsection{Streamflow}

Table 2 shows that streamflow period (seasonal period for which the catchment outlet exhibits a nonzero discharge, shown between dashed lines in Figure 4) starts between $36 \%$ and $43 \%$ of yearly cumulative precipitations, which is a rather constant threshold for such highly variable hydrological years. This implies different cumulative precipitation amounts for the initiation of the flow period (between 395 and $664 \mathrm{~mm}$ in the period sampled). Precipitation temporal distribution is of primary importance for the initiation of flow, and Figure 4 shows, for instance, that flow ceased twice during the dry 2011 year due to insufficient precipitation within the wet season. At a larger scale $\left(105 \mathrm{~km}^{2}\right)$ including the study area, the onset of seasonal streamflow can be approximated by comparing mean precipitation and mean reference evapotranspiration over a 14 day time window: if precipitation exceeds reference evapotranspiration, then streamflow may occur (L. Séguis and C. Peugeot, personal communication, 2014). At the small scale in Nalohou, this 
(a) EOF, mode 1: CG5

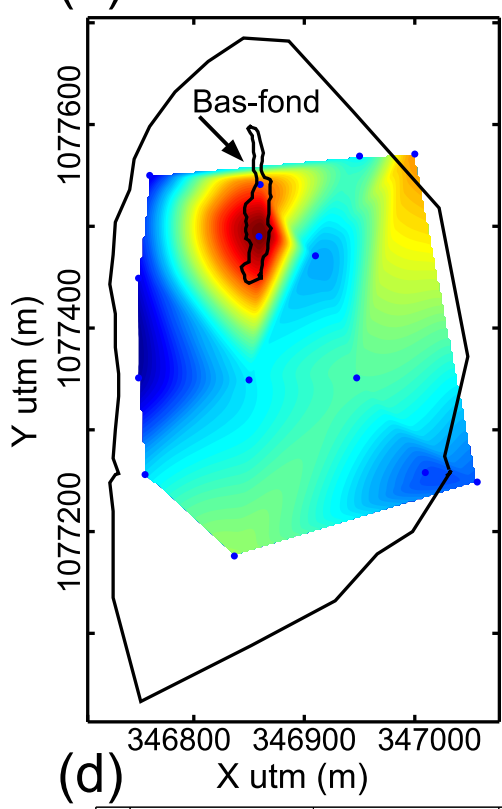

$\mu$ gals

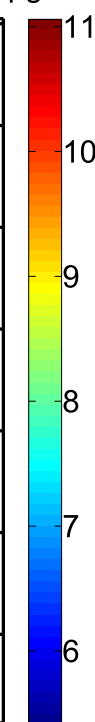

(b)

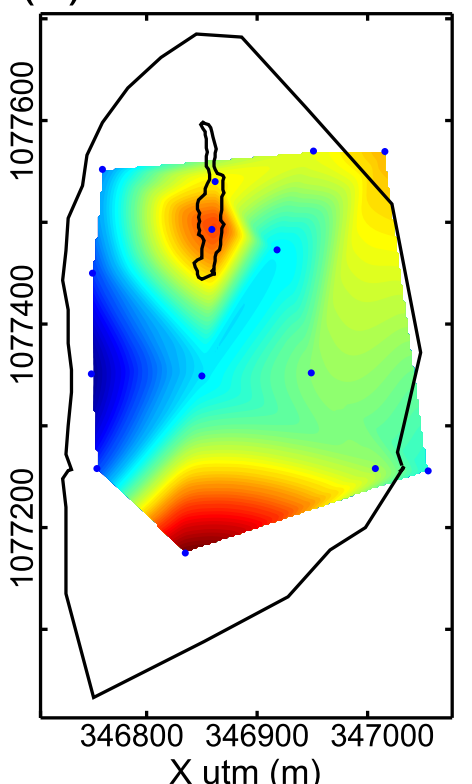

$\mathrm{mm}$

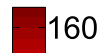

(c)
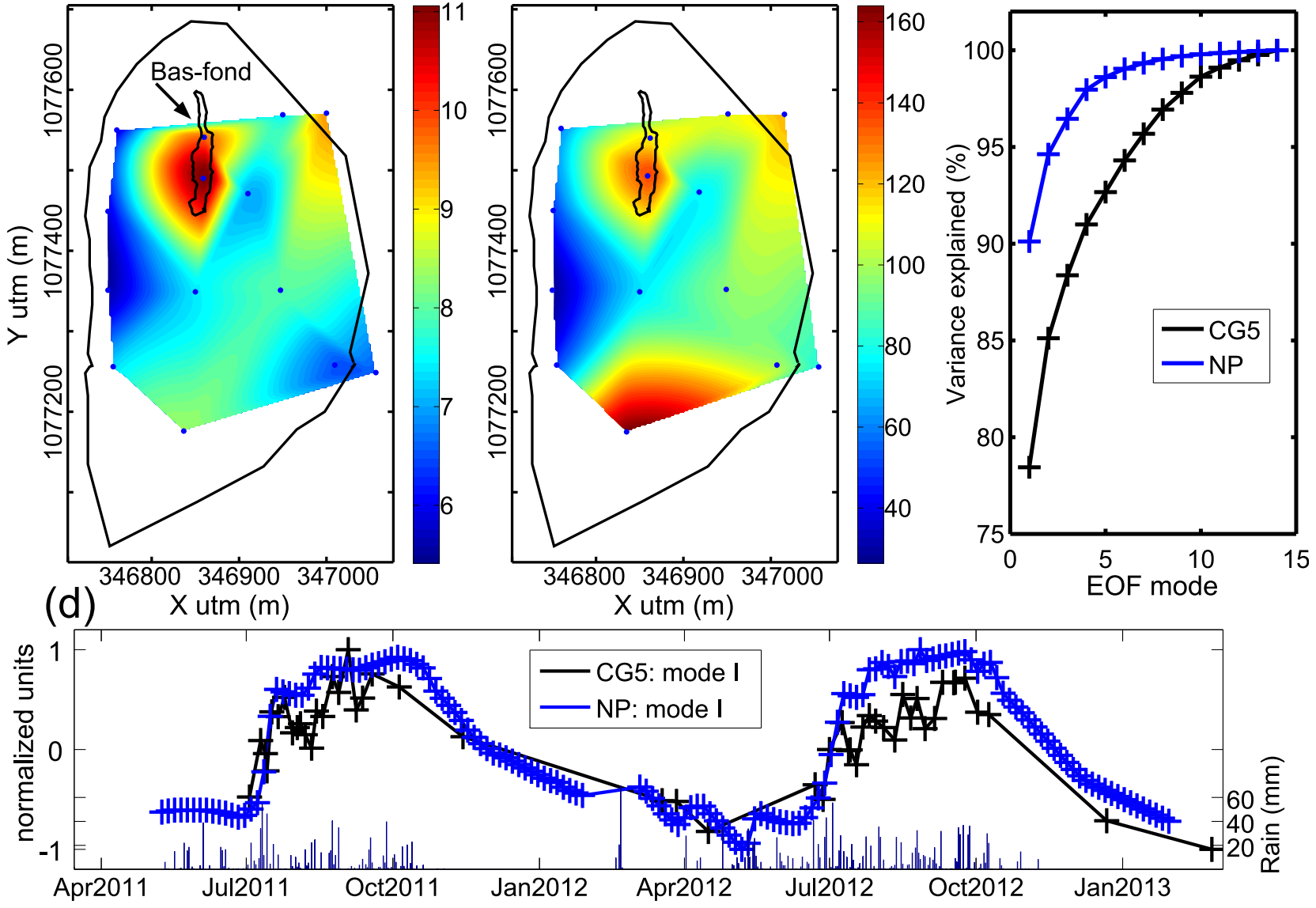

Figure 11. EOF results. (a) Mode I EOF for hybrid gravity data. (b) Mode I EOF for NP data. (c) Cumulated variance explained for each EOF mode for each data set. (d) Expansion coefficients of mode I for hybrid gravity data and NP data and daily precipitation.

relationship has been tested and is not as clear. The precipitation amount threshold for the initiation of flow may also result from a memory effect, in that if dry years follow wetter years, these dry years therefore need less precipitation to fill the storage capacity and activate base flow. In contrast, if wetter years follow dry years, these wetter years need much more precipitation to activate base flow.

The choice of the Eckhardt filter for base flow separation may not be the best approach, because the catchment size is smaller than catchments for which it was originally designed [Eckhardt, 2005], and the time constants for the system responses (e.g., recession) are small. However, it produces realistic results (1) when time series are zoomed in at the event scale, (2) at a larger scale when compared to geochemical data (see section 3), and 3) when analyzed with respect to a restrictive, simple approach: a quick experiment showed that the yearly cumulated total streamflow occurring between 0 and $2 \mathrm{~h}$ after each precipitation event higher than $4 \mathrm{~mm} \mathrm{~h}^{-1}$ accounted for, on average, $10 \%$ of the yearly cumulated total streamflow for years 2009-2012. These 10\% encompass both direct runoff and base flow occurring during the event, showing

\begin{tabular}{|c|c|c|c|}
\hline Year & $\begin{array}{c}\text { Yearly } \\
\text { Cumulative } \\
P(a)(\mathrm{mm})\end{array}$ & $\begin{array}{l}\text { Cumulative } \mathrm{P} \text { at } \\
\text { the Streamflow } \\
\text { Onset (b) (mm) }\end{array}$ & (b)/(a) \\
\hline 2008 & 1213 & 462 & 0.38 \\
\hline 2009 & 1484 & 562 & 0.38 \\
\hline 2010 & 1528 & 664 & 0.43 \\
\hline 2011 & 949 & 395 & 0.42 \\
\hline 2012 & 1422 & 517 & 0.36 \\
\hline
\end{tabular}
the minor contribution of quick flow to annual amounts. Within the whole range of subsurfacedriven streamflow, there is a continuum between fast, event-driven interflow ("shallow groundwater") and slower groundwater drainage [e.g., Jencso and McGlynn, 2011].

\subsection{Recession Analysis}

A quick analysis of streamflow and water table data from the bas-fond reveals that the bas-fond 


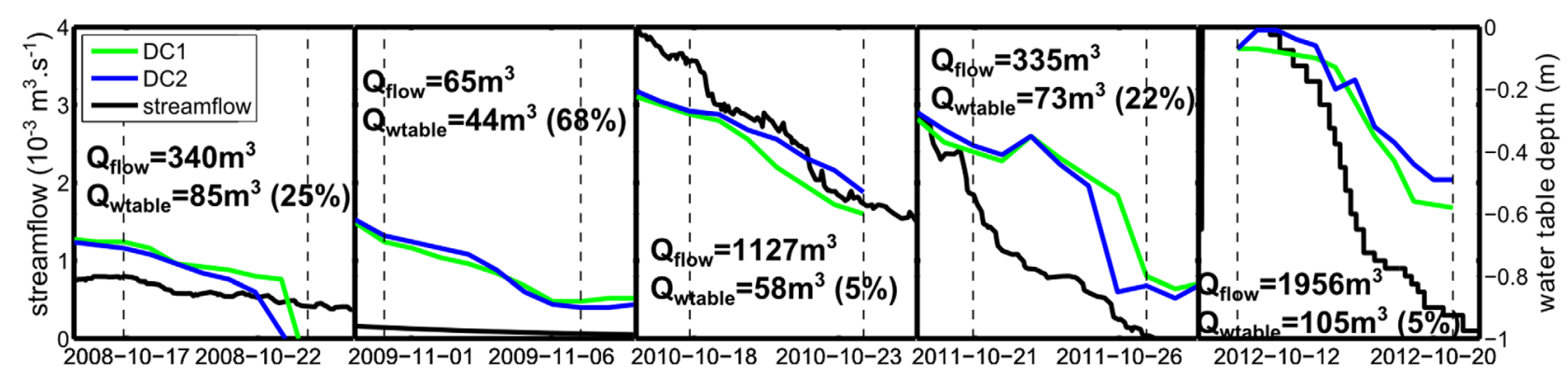

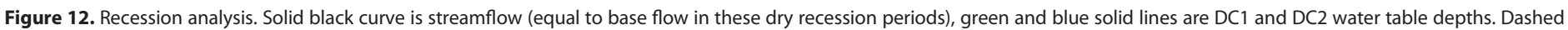
vertical lines indicate the period on which water budgets were performed. $Q_{\text {flow }}$ is the amount of streamflow water on the period, $Q_{w t a b l e}$ is the expected amount of water from water table decrease times bas-fond area, times a $10 \%$ specific yield. Percentage in brackets indicates the proportion of $Q_{w t a b l e}$ in $Q_{\text {flow }}$.

area alone does not explain all the streamflow at the outlet. This requires that different recession periods in which no rain occurred be considered at the end of each rainy season. The output volume of water during this period was compared to the expected bas-fond contribution. This contribution was defined as the water table decline in the DC station (DB and DA showing similar behavior; Figure 6) times a specific yield estimate of 0.1 , which is an upper bound for the area, as derived from previous studies [see e.g., Descloitres et al., 2011], and multiplied by the bas-fond area (i.e., $2100 \mathrm{~m}^{2}$ ). The average time series of the two different shallow wells ( $1 \mathrm{~m}$ deep) in DC (Table 1 ) is taken as the water table.

The results vary between years but in general show that a much wider contributing area is needed to provide the outflow of water from the catchment (Figure 12). This result would be further amplified if evapotranspiration in the bas-fond were taken into account. Variability in the results is likely due to the history of connectivity linked with antecedent precipitation: if the recession period is chosen late, because light rains fell without feeding the water table much for instance, the spatial connectivity between saturated areas is already low, and only the bas-fond and some small contributing areas remain. If the recession occurs early in the season, it is likely that the connectivity of saturated areas to the bas-fond is still high, which maintains a consequent output flow. A good proxy for the extent of the contributing area is therefore the water table in the bas-fond, because it defines the saturated thickness implied by the flow: the higher it is, the more water can flow out, sustained by upstream areas, and therefore the more extensive the contributing area is.

This analysis shows the need to call for a much wider contributing zone than the bas-fond itself. The strong increase in base flow with increasing precipitation (Figure 5) means that with wetter years, the connectivity is increased, either spatially or temporally, or both.

\subsection{Water Storage as a Marker for Contributing Areas}

Observation wells around the bas-fond (i.e., 18, 19, 20, 21, and TF) show a capping behavior during the flow period, while precipitation still occurs. This observation suggests lateral transfer activation. A signature from this feature is also present in WSCs such as observed by NP and gravimetry, when smaller seasonal amplitudes imply that water accumulates less in such places. The first result derived from the EOF analysis is the good match between gravity and WSCs derived from NP, for both temporal and spatial patterns. Identified behaviors are related to features present in the lithological model. The bas-fond clearly exhibits stronger seasonal amplitudes than other places. This is further amplified by the fact that the water admittance in such areas is approximately $20 \%$ lower than other parts of the catchment, due to topographic effects (see Appendix B). The topography effects would imply lower amplitudes in the bas-fond, which has not been observed. The western part, with a clayey H3 layer overlain by a hardpan in the H2 layer, in both data sets shows low amplitude, together with the immediate upstream zone, i.e., stations 21 and TF (Figure 1d). The south-east (uphill) and north-east areas exhibit an average value, with some discrepancies between stations 23 and 6. Local discrepancies may be attributed to the footprint area of each method $(0.3 \mathrm{~m}$ around the access tube for NP and $100 \mathrm{~m}$ around the station for gravity), but in general the comparison is satisfactory. One should recall here that the potential effect of vertical motion of station pillars as evidenced from the leveling survey in section 3.2.2 and the Appendix B leads to an increase in gravity (sinking motion) of the stations in the western area. However, they show the smallest amplitude in the catchment. This further underlines their distinguishable effect. 
In terms of temporal dynamics, Mode $1 \mathrm{ECs}$ for each data set (gravity, NP, Figure 11d) show slight differences between 2011 (949 mm of rain) and 2012 (1422 mm of rain). Furthermore, the gravity signal (Figure 11d) differs significantly from the base station's gravity signal (Figure 3), meaning that most stations in the network tend to behave differently than the base station. This is also observable in Figure 10, in that most stations deviate significantly from the zero line (the base station). The correlation coefficient between the two time series (ECs for gravity changes and NP-derived WSCs) is 0.86 . Due to a higher sampling frequency, NP-derived Mode 1 ECs clearly show two rates in the recession period from mid-September to June of the following year: first a high rate until November followed by a lower rate. This could be associated with groundwater redistribution processes identified in the area: shallow groundwater storages provide base flow until rivers dry up around November and then slow groundwater depletion is attributed to transpiration in the riparian zones [Séguis et al., 2011b; Richard et al., 2013].

Land use/land cover is rather homogeneous across the catchment, with mainly fallows and cultivated areas. Only bas-fond fringes and the Ara riparian zone are covered by more trees. Measurements from a largeaperture scintillometer across the Ara catchment [Guyot et al., 2009, 2012] sampling different land covers, as well as the Eddy-covariance flux station located on cultivated and fallow plots (at station TF, Figure 1d) [Mamadou et al., 2014] show that during the wet season, actual evapotranspiration reaches reference evapotranspiration [Richard et al., 2013]. Therefore, spatial variations in seasonal WSCs due to evapotranspiration can only arise from different evapotranspiration rates during the dry season. However, the flux station located in station TF shows a low evapotranspiration during the dry season [Mamadou et al., 2014], although the permanent water table at this station is nearly the shallowest of the catchment, remaining shallower than $3 \mathrm{~m}$ deep. Significant evapotranspiration during the dry season is expected from the persistent vegetation [Guyot et al., 2012], mostly located in the Ara riparian area and bas-fond fringes. This could explain to some extent the higher seasonal WSCs in the bas-fond, but not differences among other stations of the catchment.

Lateral transfers are more likely to produce a water table capping shape, to limit water accumulation in basfond surrounding zones and to favor bas-fond water storage accumulation. This would mean that most of sampled stations actually contribute to lateral transfer toward the bas-fond, and eventually to base flow. These stations sample the permanent aquifer. However, based on geochemical measurements at a larger scale, Séguis et al. [2011b] concluded that base flow was fed by the temporary perched water table (i.e., water with a short residence time, with low mineralization). To reconcile this observation with our findings, geochemical measurements should be undertaken within all observation wells, following a vertical sampling procedure, to assess the importance of stratification. Due to the vertical permeability structure of soils, with usually lower permeability with increasing depths, it is possible that shallow water within the same soil column is much less mineralized and has a smaller residency time than deeper water.

\subsection{Conceptual Model}

Different behaviors in seasonal storage are related to soil and geological features. A conceptual model was built on the interpretation of the different data sets (Figure 13). In this figure, two cross sections (W-E, Profile A in Figure 1d; and S-N, Profile B in Figure 1d) are shown at (1) the driest period in terms of water storage in the catchment (around May), before the flow period (top plot) and at (2) the wettest period when water table is the shallowest and water storage is maximal during the flow period (around September, bottom plot). Unit colors are based on relative permeability between units: the darker the color, the less permeable the material is. The water table is drawn from observation wells and hypothesized hydrological behavior within units for the interpolation between observation wells.

\subsubsection{Dry Season}

During the dry season, NP data show the clay unit in the western area maintains a high water content above the water table. Underneath the bas-fond, the water table is quite low, within a fissured basement unit that is expected to be more permeable than the clay unit. On the east bank, the water table depth is shallower within the less permeable saprolite unit, and slightly deeper in another fissured basement unit. In the S-N cross section, the permanent water table does not reach the surface, and the Ara River remains dry. The deep water table below the bas-fond is expected to be due to the higher permeability in the fissured basement than in the more clayey saprolite, or clay units. Depletion of the permanent water table during this period is thought to be caused by transpiration in the riparian zones downstream from the catchment 

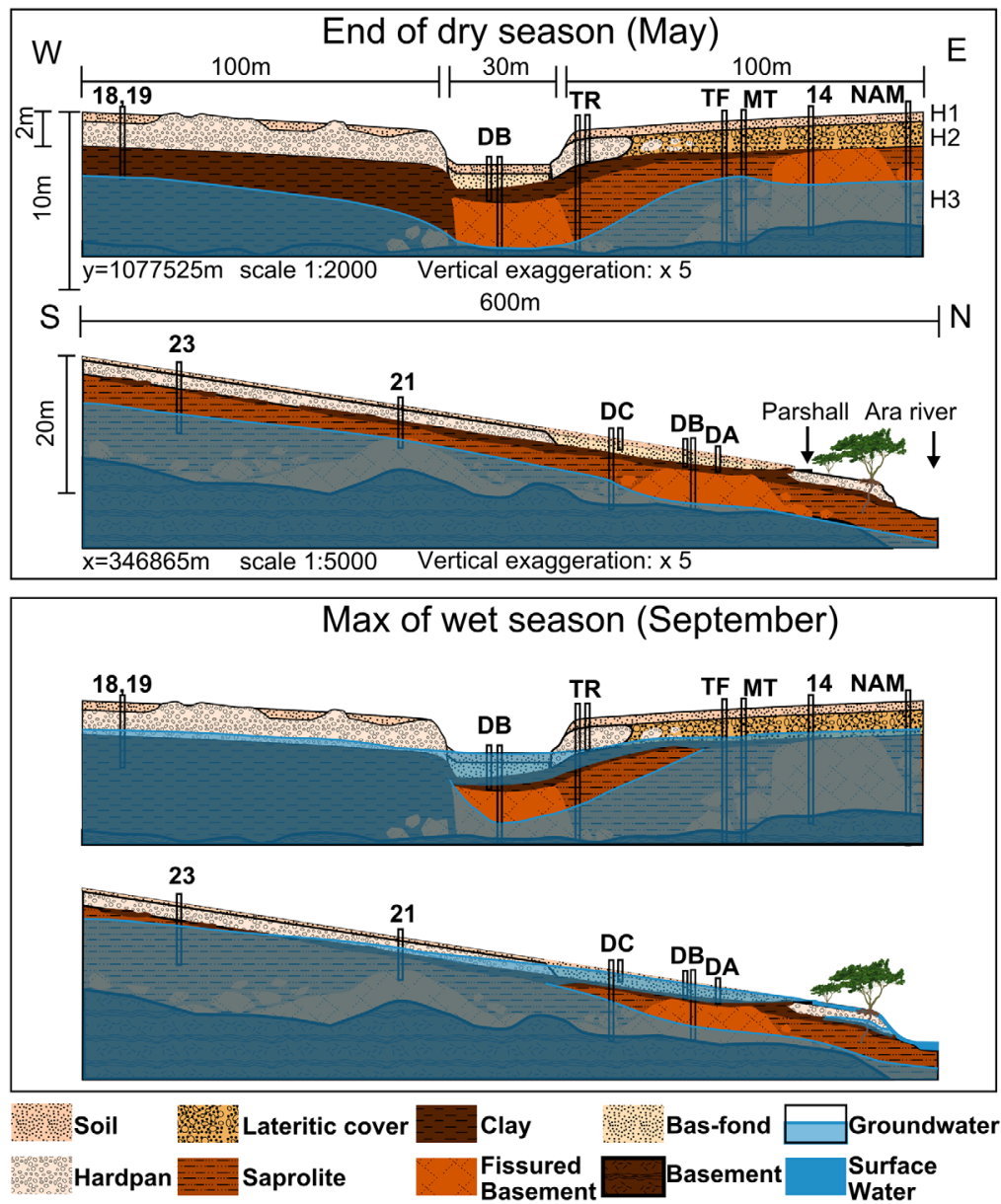

Figure 13. Conceptual model. W-E and S-N cross sections of the catchment. (top) The driest period in terms of water storage in the catchment. (bottom) The wettest period. Unit colors are darker for less permeable material. Scale is different between W-E and S-N profiles.

[Séguis et al., 2011b; Richard et al., 2013], although regional drainage (e.g., within the fissured basement unit) has not been discarded so far.

\subsubsection{Wet Season}

During the wet period, rainwater percolates quickly through the macroporous hardpan on the western area, and rapidly saturates the clay above the water table. Once the permanent water table reaches the highly permeable hardpan, quick lateral transfer is triggered, which initiates the capping shape of water table and prevents the WSCs from increasing further, as observed in NP and gravity data. The shallow perched aquifer in the bas-fond is fed by rainwater infiltration and by lateral subsurface transfer, mostly from the western bank, which shows the lowest seasonal WSC amplitude (Figure 11). Subsurface water transfer to the bas-fond from the east bank and uphill (southern) areas is made possible by a permeability contrast between the laterite and saprolite horizons. This contrast is less than between hardpan and clay on the west bank, but enhanced by the presence of clayey layers observed at the interface between layer $\mathrm{H} 2$ and layer $\mathrm{H} 3$ in most drill cuttings. This contrast and clayey layers generate a perched water table within the laterite or hardpan layer by an infiltration-excess process, as observed in station TR's shallow observation well. Such perched water tables have been described by Séguis et al. [2011b] and modeled by Richard et al. [2013], based on nearby observation wells outside the catchment. Brabant [1991] observed a similar clay layer, which forms the base of a perched groundwater during the wet season underneath a bas-fond in Cameroon and in its surroundings some $2 \mathrm{~m}$ deep. The same observation was made locally in the upper Ouémé valley by other authors [Giertz and Diekkrüger, 2003]. This results in an uncommon dry wedge feature, because the permanent water table below the bas-fond (e.g., DB and DC deep observation wells) remains disconnected from the shallow perched groundwater but is still connected laterally with the permanent water table of other areas. 
On the S-N cross section, the same dry wedge is inferred, because station 21 behaves similarly to station TF. Therefore, the shallow bas-fond aquifer is also fed from the upstream permanent water table, within the high permeability hardpan unit, above the clay layer and less permeable saprolite layer. Although an uncommon feature, this dry wedge may be found in other places in the Sudanian area. Although only focusing on the first few meters of the soil profile, Brabant [1991] draws a complete picture of humectationdesiccation cycles in a similar watershed in Cameroon, leading to a bas-fond [see Brabant, 1991, Figures 5.10-V.17]. Perched groundwaters occur during the wet season above clayey layers in the downstream section of their catchment and above fresh rock layers in the upstream section. Since Brabant only used an auger for drilling, the permanent water table during the dry season within the harder material upstream may have been missed (not sampled). This feature should be investigated in other areas to assess its importance.

Differences in permeability between the fissured basement and the saprolite unit also result in a lower water table in the deep DB observation well than in the deep DC observation well. The water table below the Ara River may or may not reach the riverbed. At larger scales (13, 105, and $\left.586 \mathrm{~km}^{2}\right)$ including the study area, previous studies using geochemistry have shown that the contribution of permanent groundwater (identified by high water mineralization) to streamflow is negligible and that permanent groundwaters are disconnected from the streams [Kamagaté et al., 2007; Séguis et al., 2011b]. Field observations show that a perched water table within the hardpan exfiltrates water above the river bed, across the slope break in the downstream section. When the bas-fond is saturated, it generates base flow and some contributions to runoff arise from saturation overland flow on the bas-fond surface.

\subsubsection{Discussion on the Conceptual Model}

The interpretation of the capping behavior in the water table-a marker of lateral transfer toward the catchment outlet through bas-fond interflow-should be tempered. Key parameters controlling WSC-discharge relationships are diffusivity and distance from the observed WSCs to discharge features [Leake, 2011]. Only a qualitative discussion can be undertaken here. Due to the high permeability of the $\mathrm{H} 2$ layer and the fact that all stations are closer to the bas-fond than surrounding bas-fonds (Figure 1c), it is likely that WSCs observed at locations where capping occurs are actually indicators of water transfer toward the bas-fond outlet. Also, WSCs from both NP data and hybrid gravity data exhibit greater seasonal amplitudes in the bas-fond than anywhere else, suggesting an accumulation zone.

As a tentative summary, the hydrology of Nalohou comprises two linked systems: a slow system and a faster system. The slow system is composed by the permanent water table that absorbs interannual variations, acting as a buffer with memory effects [see e.g., Séguis et al., 2011b, Figure 4b; Vouillamoz et al., 2015]. The fast system is composed of the perched aquifer joining the permanent water table upstream and laterally, which quickly exfiltrates excess water through base flow. While the permanent water table is linked to the bas-fond discharge feature during the wet season, this is not true during the dry season, and the discharge mechanism for this groundwater remains unclear, although riparian evapotranspiration is a good candidate. This combined system may help explain variable precipitation thresholds for the flow period initiation. From the proposed conceptual model, base flow amplitude is linked to the spatial extent of the contributive areas: the shallower the permanent water table is, the more extended permanent water table is within the transmissive $\mathrm{H} 2$ layer and toward the shallow bas-fond system, and the greater the base flow amplitude is. Therefore, after a dry year or a short wet season (e.g., early dry season), the permanent water table reaches low levels at the end of the dry season, and a high precipitation threshold is needed to refill the permanent water table and generate seasonal base flow. After a series of dry years, some distant areas (to the outlet) may not even reconnect with the fast system, resulting in highly nonlinear responses to changes. Such effects may combine with temporal precipitation patterns at the wet season onset to explain variable precipitation thresholds for the flow period initiation.

This study proposes that the permanent water table may actually contribute to base flow in this environment, which has not been considered before, on the basis of hydrological and geochemical data [Kamagate et al., 2007; Séguis et al., 2011b]. However, only the upper section of the water table, located within a higher permeability unit is contributing to base flow, similarly to interflow processes. If the geochemical signature of this permanent water table is layered during the wet season, and if water sampled in their shallow saturated layers is similar to water from the outlet, then the conclusions from Séguis et al. [2011b] can be reconciled with the present study. These hypotheses still need to be verified. 


\section{Conclusions}

In the elementary Nalohou basement catchment (North Benin) of the Sudanian area, streamflow represents about $10 \%-15 \%$ of the annual water budget and is composed of $73 \%-87 \%$ of base flow, which originates from a small bas-fond, at the headwaters of the whole hydrological system. This budget is representative of larger areas in the region [Séguis et al., 2011b]. Such predominance for base flow, as in many other tropical contexts, calls for focusing on the spatiotemporal dynamics of catchment storage, a state variable known to be part of the control system for base flow generation.

Seasonal WSCs have been analyzed at the catchment scale from observations of NP-derived soil moisture profiles, hybrid gravimetry, and water tables. The dense data set of microgravity data showed a good match with NP-derived WSCs, as demonstrated by the similarity in the first mode of the EOF analysis for each field. The correlation coefficient between associated expansion coefficients is 0.86 . Both data sets show strong seasonal WSC amplitude in the bas-fond, while much lower amplitudes are found in western areas where thick $(2 \mathrm{~m})$, porous and permeable hardpan covers low-permeability clay material. Some stations surrounding the bas-fond also seem to have small amplitudes, while upstream and eastern stations show greater amplitudes. Stations showing a low amplitude generally exhibit a water table capping behavior, marked by a fast increase in storage, followed by a plateau shape while the rainy season follows its course. Observed WSC features are coherent within similar lithology units, such as derived from resistivity data and drill log cuttings.

The conceptual model derived from crossing different data sets is made of a slow and a fast system. The slow system is composed by the permanent water table, which is recharged by vertical percolation during the wet season. Discharge mechanisms for this water table during the dry season are unclear, but likely to be driven by riparian evapotranspiration in the downstream section of the catchment. The fast system, only present during the wet season, is composed of the shallow part of the permanent water table away from the bas-fond and the perched groundwater in the bas-fond and surrounding areas. All these groundwater features are assumed to be hydraulically connected laterally within a soil layer that is more permeable than the underlying material. This system discharges in the catchment outlet. Although it was previously assumed that the permanent water table was always disconnected from streamflow in the area [e.g., Séguis et al., 2011b], this study proposes an alternative model where the upper layers of the permanent groundwater may contribute to base flow.

The use of hybrid gravity data is of primary importance in such a study, because of the footprint area of each station $(<100 \mathrm{~m})$, which means that almost all parts of the catchment could be sampled (with more or less weight depending on the distance to the closest station). Another advantage is that even if hybrid gravity requires substantial processing, calibration is not necessary. For instance, calibration issues in NP used in the present study prevented us from quantitatively exploiting NP data. The size of the footprint is fundamental, because it obviates the need for strong assumptions when interpolating point measurements (such as NP-derived soil moisture or the water table). Even though the match between hybrid gravity data and NP-derived WSCs is globally satisfactory, local discrepancies could have arisen from the nonrepresentativeness of single NP stations.

Areas with distinct water storage behaviors have now been identified in the catchment. The conceptual model resulting from this study combined with information from other variables observed on the catchment (the chemical signature of the different reservoirs, evapotranspiration, etc.) will be analyzed in the future with respect to an integrated hydrological model developed at the catchment scale.

\section{Appendix A: Neutron Probe Calibration}

The neutron probe (NP) calibration is based on the following linear relationship [IAEA, 2003]:

$$
\theta=a+C R \cdot b,
$$

where $\theta\left(\mathrm{m}^{3} / \mathrm{m}^{3}\right)$ is the soil water content and $C R$ (neutron counts/neutron counts) is the counting rate (i.e., the ratio of the observed neutron counts to a standard from observed neutron counts in $100 \%$ water, that is, a water tank). The retrieval of calibration parameters $(a, b)$ for each soil class identified is based on the regression from $998(\theta, C R)$ couples acquired during the drilling process. Gravimetric water content was 


\begin{tabular}{|c|c|c|c|c|c|c|c|c|}
\hline Type & $\mathrm{m}$ & $\sigma(\mathrm{CR}, \theta)$ & B & a & $\sigma^{2}(\mathrm{e})$ & $\sigma^{2}(\mathrm{~b})$ & $\sigma^{2}(\mathrm{a})$ & $\sigma(\mathrm{a}, \mathrm{b})$ \\
\hline Soil & 142 & 0.0058 & $3.15 \mathrm{E}-01$ & $-1.20 \mathrm{E}-03$ & $1.80 \mathrm{E}-03$ & $6.76 \mathrm{E}-04$ & $7.12 \mathrm{E}-05$ & $-2.19 \mathrm{E}-04$ \\
\hline Laterite & 260 & 0.0045 & $3.71 \mathrm{E}-01$ & $-5.54 \mathrm{E}-02$ & $1.40 \mathrm{E}-03$ & $4.65 \mathrm{E}-04$ & $1.24 \mathrm{E}-04$ & $-2.41 \mathrm{E}-04$ \\
\hline Alterite & 373 & 0.0078 & $3.51 \mathrm{E}-01$ & $-5.83 \mathrm{E}-02$ & $2.00 \mathrm{E}-03$ & $2.36 \mathrm{E}-04$ & 7.07E-05 & $-1.29 \mathrm{E}-04$ \\
\hline Clay & 62 & 0.0019 & $3.68 \mathrm{E}-01$ & $3.03 \mathrm{E}-02$ & $4.50 \mathrm{E}-03$ & $1.41 \mathrm{E}-02$ & $6.80 \mathrm{E}-03$ & $-9.80 \mathrm{E}-03$ \\
\hline Bedrock & 161 & 0.0008 & $1.02 \mathrm{E}-01$ & $-4.90 \mathrm{E}-03$ & $2.54 \mathrm{E}-04$ & $1.93 \mathrm{E}-04$ & $1.85 \mathrm{E}-05$ & $-5.98 \mathrm{E}-05$ \\
\hline
\end{tabular}

obtained by weighing drilling residuals (about $100 \mathrm{~cm}^{3}$ ) from each depth at the time of the drilling, to restrict sample drying, and then weighing after they were dried in an oven $\left(180^{\circ} \mathrm{C}, 1\right.$ day). Dry bulk densities were derived from gamma probe measurements at the same depths to infer volumetric water contents $(\theta)$.

The calibration results are shown in Table A1. After calibration, total WSCs are deduced from NP moisture variations $(\Delta \theta)$ between two dates using the trapezoidal method:

$$
W S C=\Delta \theta_{0} \cdot z_{0}+\sum_{i=0}^{n-1} \frac{\left(\Delta \theta_{i}+\Delta \theta_{i+1}\right)}{2} \cdot\left(z_{i+1}-z_{i}\right),
$$

where $z$ is measurement depth. Using a method described by Vandervaere et al. [1994], Hector et al. [2013] showed the mean standard deviation associated with the WSC calculation to be $11.6 \pm 10 \mathrm{~mm}$ at the FG5 location.

\section{Appendix B}

\section{B1. Microgravity Survey Design}

General considerations. Microgravity studies for hydrology usually concern amplitudes ranging from a few microgals up to hundreds of microgals and spatial coverage of a few meters up to tens of kilometers in various environmental contexts. Depending on these conditions, specific survey designs have to be defined; in particular the number of stations, locations and reoccupations, measurement times, and loop geometry (loops are needed for instrumental drift control). All these considerations impact data accuracy. For instance, instrument transportation and hence distance between stations is known to affect accuracy [McClymont et al., 2012; Masson et al., 2012; Pfeffer et al., 2013], although some authors mentioned a much weaker dependence [Lambert and Beaumont, 1977]. Gettings et al. [2008] report on a number of studies using many reoccupations and/or several gravimeters to constrain drift and detect nonlinear drifts and tares. Requirements and advices for high-quality survey designs can be found in Seigel et al. [1995].

Expected CG5 uncertainties. One may refer to accuracy as the instrument's ability to measure the true value (the difference between measured gravity and the true gravity), to precision as the standard error of repeated measurements (repeatability), and to resolution as the smallest gravity change that can be provided by the instrument [Christiansen et al., 2011c]. Because processing involves inversion for drift adjustment, one may also refer to a posteriori precision, or simpler to uncertainty, as the a posteriori standard deviation on each station value after drift adjustment.

Studies report on CG5 uncertainties ranging from 0.4 to $3 \mu \mathrm{Gal}$ in favorable conditions, e.g., metric distances with several reoccupations [Merlet et al., 2008; Christiansen et al., 2011c]. Then, the uncertainty for temporal gravity difference at a station is the square root of the quadratic sum of each uncertainty, i.e., 0.6-4.2 $\mu \mathrm{Gal}$. Finally, gravity variations are often considered significant when they are higher than twice this latter uncertainty [Jacob et al., 2010; Naujoks et al., 2010], i.e., 1.2-8.4 $\mu$ Gal. This uncertainty calls for a rigorous protocol definition, if one has to seek such weak amplitude signal.

\section{B1.1. Loop Geometries}

Number of stations and reoccupations. In this study, the target area is a small catchment size is $0.16 \mathrm{~km}^{2}$ allowing for an easy and fast transportation by foot. However, the expected spatial variations of WSC are weak with respect to standard instrument uncertainty, seasonal WSC uphill being only about $12 \mu \mathrm{Gal}$. 
Consequently, several station reoccupations within different loops should be considered. Although some authors state that at least three reoccupations are needed to detect discrepancies [Ferguson et al., 2007; Christiansen et al., 2011c], we limited our survey design to only two reoccupations, to allow a sufficient basin coverage (number of stations), but we stayed long enough at each station to make sure the sensor was stabilized (see next section). This was found to be the best compromise between spatial coverage and expected accuracy.

CG5 network geometry. The network was composed of 15 stations within two main loops (loop = itinerary). The first loop (in order: base station - 18 - 19- DC - DB - TF - 14 - NAM - base station) was repeated twice in the morning and the second one (in order: base station - 6-23-M - 20 - 21 - 22 - SG - base station) twice in the afternoon. Because measurements were densified during the rainy season, precipitation was likely to occur while performing the survey. Diurnal peak of precipitation probability occurs just after midnight [Vollmert et al., 2003], and each survey was therefore limited to one single day. In other contexts, it may be worth to repeat loops over several days to improve accuracy, or to use several gravimeters when possible [Naujoks et al., 2010; Mouyen et al., 2013; Pfeffer et al., 2013]. If precipitation occurred during the day, the survey was cancelled and postponed to the next day. However, as showers sometimes happen in the late afternoon [Vollmert et al., 2003; Judex and Thamm, 2008], we chose to imbricate loops 2 and 3, by replacing three stations from loop 2 (18 - 14 - NAM) by three stations from loop 3 (6 - 22 - 21). If no rain occurred, the opposite scheme was done by replacing the same three stations from loop 4 by the three stations from loop 2. If rain occurred in late afternoon, loop 4 was shortened or cancelled, but imbrications allowed all loops to be tied together, and therefore cancelling dependency of some stations to a single loop. For a detailed analysis and description of gravity networks, see for instance Lambert and Beaumont [1977] and Torge [1980].

Base station. To tie the CG5 network to the SG time series, we wished to set the reference station (first and last station of each loop) on the SG pier. However, as there was no space left on the pier and measurements were to be taken on the unstable ground (tilts of this station are the most instable ones of the whole network), the reference station was eventually set on the FG5 pier $\left(1 \mathrm{~m}^{3}\right), 7 \mathrm{~m}$ South-West of the SG pier. This station was always reoccupied in less than $3 \mathrm{~h}$ to preserve the drift linearity assumption. SG station was kept in the network to check for possible discrepancies between FG5 and SG locations, but poor data precision discarded its use in the paper.

\section{B1.2. Measurement Protocol}

Operators. A consequent measurement protocol had to be defined to reach the best possible accuracies. As an unknown number of operators were expected, the protocol had to be clear enough, to limit the operator subjectivity. However, this was eventually slightly relaxed, as a maximum of three people were to be involved with the transportation during the entire campaign, while only two of them were actually in charge of the measurements, and often working together.

Transportation. The instrument was carried by two operators, who held a rod on which the gravimeter bag was hung by the handles (shown in Figure 9a). This was found to be an efficient way to reduce transportation effects, clearly seen in the stabilization time of the device [see e.g., McClymont et al., 2012, Figure 4] the first minutes after setting up the instrument at a station.

Instrumental height. As vertical movements strongly impact gravity changes $(\approx 0.3 \mu \mathrm{Gal} / \mathrm{mm}$ using a nominal free-air gradient), stations were pillars made of concrete $(0.5 \mathrm{~m} \times 0.5 \mathrm{~m} \times 0.5 \mathrm{~m})$ to limit the consequences of a soft ground. For each survey, the instrument was located exactly at the same point, and kept at the same azimuth thanks to screws stuck in the concrete pillar. The height with respect to the pillar was kept constant with the use of a brass ring fixed to one foot of the instrument's tripod, as suggested by Montgomery [1971].

CG5 shielding. The CG5 and its tripod were shielded from wind and direct sun exposure by a dustbin covered with insulating material.

Single measurement duration. The CG5 was sampling at $6 \mathrm{~Hz}$, averaging over $60 \mathrm{~s}$ to produce one single measurement, standard deviation, and mean error (assuming normal distribution of samples). Merlet et al. [2008] showed in their study that the Allan deviation of their CG5 reached $1 \mu$ Gal after $40 \mathrm{~s}$, to a minimum of $0.8 \mu \mathrm{Gal}$ after $85 \mathrm{~s}$ but further increased because of tidal influence. Gettings et al. [2008] also showed an 
example from raw $1 \mathrm{~s}$ data (their Figure 2), where running average converge at about $40 \mathrm{~s}$. Furthermore, after $60 \mathrm{~s}$, standard error on the CG5 display screen operating on the field always seems to have converged. In our quest for tradeoffs between accuracy and spatial coverage, we chose to keep $60 \mathrm{~s}$ data, to allow for a dynamic and fast inference of instrument stability (see next paragraph).

Measurement series and stability criteria. At a station, a first set of five measurements were taken while the operators stayed a few meters away from the instrument, before leveling was checked a first time. Another set of measurements was then taken, and operators came to check for instrument stability roughly every 5 $\min$. At any check, if tilts were out of the $0 \pm 5$ arcsec (unit is arc second) range, the instrument was leveled again. This follows Merlet et al. [2008], who found the CG5 internal tilt correction to be accurate at the $1 \mu \mathrm{Gal}$ level at \pm 20 arcsec (unit is arc second). They further managed to keep the tilts within $0 \pm 3$ arcsec (unit is arc second) in their indoor and stable pier conditions. Measurements were considered as achieved (and the gravimeter stable) when all the following criteria were reached: a minimum of 10 relevant measurements are taken, gravity changes are $3 \mu \mathrm{Gal}$ or less within five consecutive measurements, and there is no visible drift in the five last measurements (drift $<1 \mu \mathrm{Gal} / 5$ minutes).

\section{B2. Microgravity Data Processing}

The main steps of time-lapse microgravity data processing are (1) correcting data for known temporal gravity variations during a survey; (2) selecting "good" data; (3) adjusting gravity values at stations while evaluating loops drifts; and (4) analyzing uncertainties on single measurements and temporal gravity differences.

\section{B2.1. Data Corrections}

All other temporal effects on gravity but local hydrology must be removed at best from the data. Earth tides and oceanic loading are calculated using a local tide model derived from the SG data [Hector et al., 2014]. Atmospheric pressure effect is obtained using loading calculations, by convolving pressure fields from the operational model of the European Center for Medium-Range Weather Forecast (ECMWF) available at $3 \mathrm{~h}$ and $0.25^{\circ}$ resolution [Rabier et al., 2000] with the pseudostratified Green's functions [Boy et al., 2002], using the formalism of Farrell [1972] and Merriam [1992]. This loading contribution is evaluated for angular distances larger than $0.25^{\circ}$ from the station (called the "nonlocal" part) and the local contribution is computed from the local pressure records and a nominal admittance in the $0.25^{\circ}$ radius "cylinder" around the station from the same loading model $\left(-3.06679 \mathrm{~nm} / \mathrm{s}^{2} / \mathrm{hPa}\right)$. The ocean response is included in the nonlocal calculation using the MOG2D nontidal ocean model [Carrère and Lyard, 2003] which has shown to perform better than the classical inverted barometer hypothesis [Boy and Lyard, 2008; Boy et al., 2009]. Details of atmospheric corrections for the Djougou SG station can be found in Hinderer et al. [2014b] and Hector et al. [2014]. Particularly, these authors showed the discrepancies between using a single scalar admittance and such loading calculations to correct for the pressure effects.

Polar motion and large-scale hydrological effects are negligible $(<0.1 \mu \mathrm{Gal})$ within the time span of a single loop [see e.g., Hector et al., 2014].

\section{B2.2. Data Selection}

Among the recorded measurements at each station, the first ones are usually affected by a nonlinear drift due to transportation [McClymont et al., 2012]. Once the gravimeter is stabilized, the time series converges, and those measurements which are within a $3 \mu \mathrm{Gal}$ range are kept for least square adjustment, making sure the tilts are within the accepted range $(0 \pm 5$ arcsec (unit is arc second)) and no particular behavior is identified in the instrument internal temperature.

\section{B2.3. Least Square Adjustment}

Once previous corrections and selections are made for each survey, gravity values at each station and firstorder linear drifts for each loop are adjusted using the software MCGRAVI [Beilin, 2006] based on the least square inversion scheme described by Hwang et al. [2002]. A quick overview of the method can be found in Jacob et al. [2010]. Following several authors, we added a $5 \mu \mathrm{Gal}$ threshold to the observed standard deviations before the adjustment, such that if an observed standard deviation is below this threshold, it is set to this value [Jacob et al., 2010; Christiansen et al., 2011c; Pfeffer et al., 2013]. This is done to account for systematic errors which are inherently not considered in CG5 standard deviation outputs. Particularly, Christiansen 


\begin{tabular}{|c|c|c|c|c|c|c|}
\hline & \multicolumn{3}{|c|}{ Single Surveys (mm) } & \multicolumn{3}{|c|}{ Differences (mm) } \\
\hline & $29 / 6 / 2011$ & $23 / 8 / 2011$ & $31 / 8 / 2012$ & $8 / 2011$ to $6 / 2011$ & $8 / 2012$ to $8 / 2011$ & $8 / 2012$ to $6 / 2011$ \\
\hline Max. loop closure $(\mathrm{mm})$ & 14 & 4 & 7 & & & \\
\hline FG5 & 0 & 0 & 0 & 0 & 0 & 0 \\
\hline SG pier & -412 & -415 & -413 & -3 & 2 & -1 \\
\hline SG: CG5 station & -451 & -453 & -453 & -1 & 0 & -2 \\
\hline 6 & -112 & -103 & -102 & 9 & 1 & 10 \\
\hline 23 & 521 & 518 & 518 & -3 & 0 & -3 \\
\hline 22 & $-4,012$ & $-4,015$ & $-4,017$ & -4 & -2 & -5 \\
\hline 21 & $-5,027$ & $-5,023$ & $-5,023$ & 3 & 0 & 3 \\
\hline M & $-1,284$ & $-1,286$ & $-1,289$ & -3 & -3 & -6 \\
\hline 20 & $-3,985$ & $-3,990$ & $-3,995$ & -6 & -5 & -10 \\
\hline 19 & $-6,812$ & $-6,821$ & $-6,825$ & -9 & -4 & -13 \\
\hline 18 & $-10,306$ & $-10,313$ & $-10,315$ & -7 & -2 & -10 \\
\hline TF & $-7,831$ & $-7,836$ & $-7,838$ & -5 & -3 & -8 \\
\hline 14 & $-10,597$ & $-10,602$ & $-10,604$ & -6 & -2 & -7 \\
\hline NAM & $-9,231$ & & $-9,230$ & & & 1 \\
\hline DB & $-13,214$ & $-13,208$ & $-13,205$ & 6 & 3 & 9 \\
\hline DC & $-11,163$ & $-11,160$ & $-11,161$ & 3 & -1 & 2 \\
\hline
\end{tabular}

et al. [2011c] operated their CG5 on a pool from which mass variations were known, therefore controlling the accuracy (the true uncertainty). They observed that, after least square adjustment using the standard deviations from data alone, the true uncertainty is underestimated. They also noted that this threshold was subjective, and that no method to assess its value has been found yet.

\section{B2.4. Uncertainty Analysis}

The least square adjustment method allows the estimates of an a posteriori covariance matrix on gravity and drift values, given the observations and the assumption of a linear drift model. Microgravity

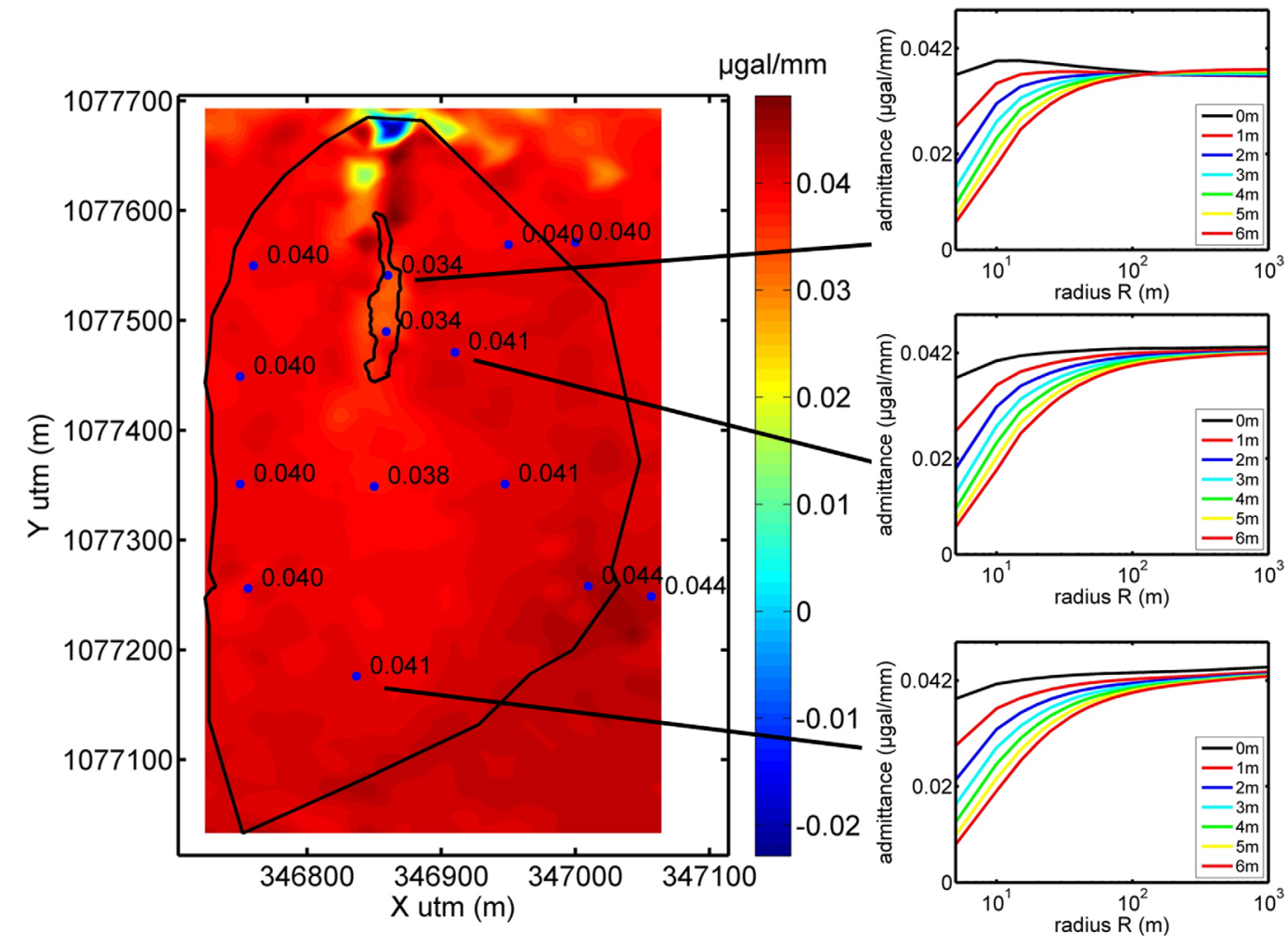

Figure B1. Water admittance: gravity effect of a $1 \mathrm{~mm}$ layer of water spread on the topography up to $1000 \mathrm{~m}$ around each grid node. Values at specific stations are shown as labels in the figure. Insert plots on the right are water admittances for a $1 \mathrm{~mm}$ layer of water spread on the topography up to a distance $\mathrm{R}$ to the station and at several depths $(0-6 \mathrm{~m})$. 
measurements and applied corrections are affected by multiple sources of uncertainties (for a review, see for instance Christiansen et al. [2011c] and Bonvalot et al. [1998] for CG3M and CG5 meters, and Metzger et al. [2002] for L\&R model D). As it is challenging to quantify each impact independently, standard errors from the least square adjustment are usually used as uncertainties estimates for a specific station measured within a specific survey. A thorough discussion on the validity of this standard error can be found in Lambert and Beaumont [1977].

Time-lapse microgravity only considers gravity changes between surveys, for which static gravity effects (free air, Bouguer, terrain, spatial rock density structure, etc.) cancel out. Standard error (uncertainty) on a gravity change between two surveys and for a specific station is the square root of the quadratic sum of respective standard errors for each survey.

\section{B3. Sensitivity Analysis of Microgravity Data}

Before interpreting residual microgravity data as local hydrology, a sensitivity analysis should be undertaken to explore other local effects on gravity, either temporal such as vertical motion, erosion, and vegetation or static such as features from the environment (topography, shelter mask, or concrete pillar) which modify the WSC-to-gravity relationship data [Van Camp et al., 2006; Kroner and Jahr, 2006; Hasan et al., 2006; Meurers et al., 2007; Creutzfeldt et al., 2008; Masson et al., 2012; Deville et al., 2012; Hector et al., 2014]. For SG and FG5 base stations, one may refer to studies of Hector et al. [2013, 2014].

\section{B3.1. Vertical Deformation}

The theoretical vertical Bouguer gradient is about $-0.2 \mu \mathrm{Gal} / \mathrm{mm}$, and small deviations from this value are expected depending on the process leading to the vertical deformation [Hofmann-Wellenhof and Moritz, 2006; De Linage et al., 2007; Mouyen et al., 2013]. If the gravimeter moves vertically as a consequence of a very local process (such as monument motion), the free-air effect is rather invoked (about $-0.3 \mu \mathrm{Gal} / \mathrm{mm}$ ). Montgomery [1971] already recognized that such effect could potentially alter the retrieval of the hydrological information. Multiple causes can induce local vertical motion of stations: thermal expansion of the monument and soil compaction [Romagnoli et al., 2003], or expansion due to clay swelling for instance [Hector, 2011] and so on. A $1 \mathrm{~m}^{3}$ FG5 monument sinking on sandy context has been modeled in the work of Pfeffer [2011]. She found an induced gravity change of less than $3 \mu \mathrm{Gal}$, likely to occur short time after pillar construction. In our case, and with smaller pillars $\left(0.1 \mathrm{~m}^{3}\right)$ and measurements starting about 3 months after pillar construction, it is likely that such an effect is negligible. Same considerations apply for the $1 \mathrm{~m}^{3} \mathrm{FG} 5$ base station which has been built more than 3 years before CG5 measurements started. Christiansen et al. [2011a] reported on an absence of vertical motion of their pillars after being stepped on by elephants. The effect of local zebus is therefore probably negligible. The amplitude range of thermal expansion of monuments of such size is also negligible ( $<1 \mathrm{~mm}$ ) [Romagnoli et al., 2003].

As clay formations are present within the water table fluctuation zone on the basin, vertical movements are still to be expected. We conducted three leveling surveys, two during the 2011 rainy season, and one in the 2012 rainy season. Results are shown in Table B1. The first survey shows the largest differences, which are quite significant for some stations (up to $13 \mathrm{~mm}$ for station $19, \approx 2.6 \mu \mathrm{Gal}$ using the theoretical vertical gradient). However, a poor acquisition protocol with large distances between temporary leveled points in the first survey resulted in larger closure errors, of up to $14 \mathrm{~mm}$. It is not possible to conclude on the vertical movement based on these data only, but despite the coherent trend that we observe (which may also be partly due to the reference station), no gravity change higher than $4 \mu \mathrm{Gal}$ should be due to vertical motion of the stations, and it is likely that the effect is actually much less. More specifically, it seems that western stations $(18,19,20$, and $M)$ show the strongest sinking motion, which would lead to substantially increase gravity in time. Drive rods that are installed to depth below the zone of water content variability might have been a better choice because they would be less susceptible to soil shrink/swell and have no masking effect.

\section{B3.2. Erosion Rates}

Erosion rates are susceptible to induce gravity changes in some contexts [Mouyen et al., 2013]. Judex and Thamm [2008] report on sediment discharge for the upper Ouémé catchment and from the outputs of a calibrated/validated SWAT model, they indicate an average production rate of 0.22 metric ton/ha/yr, with a maximum for some subcatchments of up to $2.25 \mathrm{t} / \mathrm{ha} / \mathrm{yr}$. Assuming this production is homogeneous, 
maximum gravity effect would be less than $0.01 \mu \mathrm{Gal} / \mathrm{yr}(0.225 \mathrm{~mm} / \mathrm{yr}$ of equivalent water thickness). However, local production rates may be higher, depending on environmental conditions. Yet it is likely that such an effect is negligible in the time span of our study ( $<3$ years), and without field evidences of specific erosion processes.

\section{B3.3. Vegetation}

In the Sudanian region and more specifically in northern Benin, nonperennial vegetation follows the monsoon cycle: plant growth follows cumulative precipitation pattern at the start of the rain season, and so do most cultures [Blanchard et al., 2007]. This vegetation cover can grow densely up to 2-3 m. Eventually, it is burnt by local farmers around November. One may ask the question of the potential effect on gravity of such matter-storage and water-storage compartment. For inducing a gravity change of $1 \mu \mathrm{Gal}$ (CG5 resolution), an infinite material layer of unitary density (i.e., water) on a flat terrain should have a $24 \mathrm{~mm}$ thickness, which corresponds to $24 \mathrm{~kg} / \mathrm{m}^{2}$. Blanchard et al. [2007] report on dry biomass lower than $1 \mathrm{~kg} / \mathrm{m}^{2}$ at the end of the wet season, before burning. With $90 \%$ water content, this makes a seasonal mass change of $10 \mathrm{~kg} / \mathrm{m}^{2}$, hence about less than $0.5 \mu \mathrm{Gal}$.

\section{B3.4. Topographic Effect}

The topographic effect is computed at each CG5 station using a DEM described in previous studies [Hector et al., 2013, 2014], and merged with a 3 s SRTM (Shuttle Radar Topography Mission) [Farr et al., 2007] for the far field component. The gravity effect of a layer of water spread at different depths and according to the topography is computed at each station from the extended point-mass equation provided by Leirião et al. [2009], and as a function of the extension from the station. In the case of a flat terrain, and after some distance, each solution should converge toward the Bouguer value of $0.042 \mu \mathrm{Gal} / \mathrm{mm}$ of water (as for instance in Hector et al. [2014, Figure 4]). This value is also known as the water admittance, and depends on the topography. If a gravimeter is located above a hill, the gravity effect of an infinite layer of water is higher than the Bouguer value, because more masses are present to act on the vertical gravity component with respect to a flat terrain. Computation results are shown in Figure B1. This figure shows the water admittance, and specific values at each station are plotted as labels. All stations have water admittance comprised between 0.034 and $0.044 \mu \mathrm{Gal} / \mathrm{mm}$. Lower station values are found in the bas-fond because of the surrounding higher elevations. Negative values can be found in the valley bottom, and if gravity measurements would be taken there, gravity inversion for WSC retrieval would certainly be more complex. All stations have a small footprint area (the area from where $90 \%$ of the signal does originate) of less than $100 \mathrm{~m}$, as shown in the three examples of Figure B1. Only stations located in the bas-fond exhibit some specific behavior in the near field, because of its small topographic depression. There, shallower layers undergo a decrease of the calculated gravity effect for a certain radius increase, when this radius starts to include the bas-fond banks located at higher elevations than bas-fond stations.

\section{Acknowledgments}

The authors thank many people who helped in acquiring, maintaining, and processing data and instruments in Djougou. Particularly Sarè Tahirou who was involved in all the CG5 surveys. Low uncertainties are mostly due to his calm and rigor. F. Littel for the SG, J.D. Bernard, B. Luck, N. LeMoigne, and S. Tahirou for FG5 measurements, I. Imorou, E. Pagou, T. Ouani, S. Afouda for hydrological acquisition, and G. Ferhat for topographic mapping. This study was conducted within the ANR GHYRAF project and the AMMACATCH observation system. We also thank the project partners who consented to the use of their infrastructures and provided valuable information and advices. From the Direction Générale de I'Eau (DG-Eau, Cotonou): J.C. Gbodogbé and A. Zannou, from the Abomey-Calavi University: N. Yalo. Finally, we thank L. Northrup for reading and improving the manuscript. The data can be obtained from the first author B. Hector (basilehector@gmail.com).

\section{B3.5. Pillar Effect}

No WSC can be expected from within the concrete pillar. The maximum effect from the pillar's masking role is $10 \%$ of the Bouguer plate $\left(4 \times 10^{-3} \mu \mathrm{Gal} / \mathrm{mm}\right)$ at $0.1 \mathrm{~m}$ depth and less than $2 \%\left(7 \times 10^{-4} \mu \mathrm{Gal} / \mathrm{mm}\right)$ at $1 \mathrm{~m}$ depth, which is negligible regarding CG5 accuracies. However, when the CG5 is located on the larger FG5 pillar (base station), no WSC can occur within the pillar volume, and the shelter also plays a masking role for precipitation water infiltration, stronger than for a higher elevation FG5 instrument. FG5 pillar contribution remains negligible, because the CG5 location is located on an edge, and therefore its effect is $13 \%$ of the Bouguer plate $\left(5.5 \times 10^{-3} \mu \mathrm{Gal} / \mathrm{mm}\right)$ at $0.1 \mathrm{~m}$ depth and less than $5 \%\left(2 \times 10^{-3} \mu \mathrm{Gal} / \mathrm{mm}\right)$ at $1 \mathrm{~m}$ depth. The shelter masking role in Nalohou can be important for surface WSC, but it is supposed that on a seasonal time frame, water redistribution underneath the shelter lowers its actual effect. Thorough assessment of such effect can only be derived from a modeling experiment as no hydrological sensor has been installed underneath the building.

\section{References}

Abe, M., et al. (2012), A comparison of GRACE-derived temporal gravity variations with observations of six European superconducting gravimeters, Geophys. J. Int., 191, 545-556, doi:10.1111/j.1365-246X.2012.05641.x.

Allen, R. G., L. S. Pereira, D. Raes, M. Smith (1998), Crop evapotranspiration-Guidelines for computing crop water requirements, FAO Irrig. Drain. Pap. 56, vol. 300, 6541 pp., FAO, Rome. 
Anderson, A. E., M. Weiler, Y. Alila, and R. O. Hudson (2010), Piezometric response in zones of a watershed with lateral preferential flow as a first-order control on subsurface flow, Hydrol. Processes, 24, 2237-2247, doi:10.1002/hyp.7662.

Bárdossy, A., and W. Lehmann (1998), Spatial distribution of soil moisture in a small catchment. Part 1: Geostatistical analysis, J. Hydrol., 206, 1-15, doi:10.1016/S0022-1694(97)00152-2.

Beauvais, A., M. Ritz, J.-C. Parisot, M. Dukhan, and C. Bantsimba (1999), Analysis of poorly stratified lateritic terrains overlying a granitic bedrock in West Africa, using 2-D electrical resistivity tomography, Earth Planet. Sci. Lett., 173, 413-424, doi:10.1016/S0012-821X(99)00245-9.

Beilin, J. (2006), Apport de la gravimétrie absolue à la réalisation de la composante gravimétrique du Réseau Géodésique Français, master thesis, 157 pp., Inst. Géogr. Natl., Paris, France.

Birkel, C., C. Soulsby, and D. Tetzlaff (2011), Modelling catchment-scale water storage dynamics: Reconciling dynamic storage with tracerinferred passive storage, Hydrol. Processes, 25, 3924-3936, doi:10.1002/hyp.8201.

Blanchard, M., C. Peugeot, and J. Seghieri (2007), Structure et dynamique saisonnière de la végétation sur quatre types de couvert végétal représentatifs de la diversité du bassin versant de la Donga, master thesis, 50 pp., Univ. de Montpellier II, Montpelliar, France.

Bonvalot, S., M. Diament, and G. Gabalda (1998), Continuous gravity recording with Scintrex CG-3M meters: A promising tool for monitoring active zones, Geophys. J. Int., 135, 470-494, doi:10.1046/j.1365-246X.1998.00653.x.

Boy, J.-P., P. Gegout, and J. Hinderer (2002), Reduction of surface gravity data from global atmospheric pressure loading, Geophys. J. Int., 149, 534-545, doi:10.1046/j.1365-246X.2002.01667.x.

Boy, J.-P., L. Longuevergne, F. Boudin, T. Jacob, F. Lyard, M. Llubes, N. Florsch, and M.-F. Esnoult (2009), Modelling atmospheric and induced non-tidal oceanic loading contributions to surface gravity and tilt measurements, J. Geodyn., 48, 182-188, doi:10.1016/j.jog.2009.09.022.

Boy, J. P., and F. Lyard (2008), High-frequency non-tidal ocean loading effects on surface gravity measurements, Geophys. J. Int., 175, 3545, doi:10.1111/j.1365-246X.2008.03895.x.

Brabant, P. (1991), Le sol des forêts claires du Cameroun: exemple d'étude d'un site représentatif en vue de la cartographie des sols et de l'évaluation des terres, 540 pp., IRD ed., Paris, France.

Braun, J.-J., M. Descloitres, J. Riotte, S. Fleury, L. Barbiéro, J.-L. Boeglin, A. Violette, E. Lacarce, L. Ruiz, and M. Sekhar (2009), Regolith mass balance inferred from combined mineralogical, geochemical and geophysical studies: Mule Hole gneissic watershed, South India, Geochim. Cosmochim. Acta, 73, 935-961, doi:10.1016/j.gca.2008.11.013.

Brown, G., and Rymer, H. (1991), Microgravity monitoring at active volcanoes: A review of theory and practice, ECGS, 4, $279-304$.

Bruijnzeel, L. A. (1983), Evaluation of runoff sources in a forested basin in a wet monsoonal environment: A combined hydrological and hydrochemical approach, in Proceedings of Symposium on the Hydrology of Humid Tropical Regions, pp. 165-174, Int. Assoc. of Hydrol. Sci., Hamburg.

Bruijnzeel, L. A. (1990), Hydrology of Moist Tropical Forests and Effects of Conversion: A State of Knowledge Review, 224 pp., Vrije Univ. Amsterdam, Paris.

Carrère, L., and F. Lyard (2003), Modeling the barotropic response of the global ocean to atmospheric wind and pressure forcing-Comparisons with observations, Geophys. Res. Lett., 30, 1275, doi:10.1029/2002GL016473.

Casenave, A., and C. Valentin (1992), A runoff capability classification system based on surface features criteria in semi-arid areas of West Africa, J. Hydrol., 130, 231-249, doi:10.1016/0022-1694(92)90112-9.

Chapman, D. S., E. Sahm, and P. Gettings (2008), Monitoring aquifer recharge using repeated high-precision gravity measurements: A pilot study in South Weber, Utah, Geophysics, 73, WA83-WA93, doi:10.1190/1.2992507.

Christiansen, L., P. Binning, D. Rosbjerg, O. B. Andersen, and P. Bauer-Gottwein (2011a), Using time-lapse gravity for groundwater model calibration: An application to alluvial aquifer storage, Water Resour. Res., 47, W06503, doi:10.1029/2010WR009859.

Christiansen, L., E. B. Haarder, A. B. Hansen, M. C. Looms, P. Binning, D. Rosbjerg, O. B. Andersen, and P. Bauer-Gottwein (2011b), Calibrating Vadose Zone Models with time-lapse gravity data, Vadose Zone J., 10, 1034-1044, doi:10.2136/vzj2010.0127.

Christiansen, L., S. Lund, O. B. Andersen, P. Binning, D. Rosbjerg, and P. Bauer-Gottwein (2011c), Measuring gravity change caused by water storage variations: Performance assessment under controlled conditions, J. Hydrol., 402, 60-70, doi:10.1016/j.jhydrol.2011.03.004.

Cole, K. C. (1991), Estimation of Mass Flux and Aquifer Properties Using Global Positioning System and Microgravity in the Tucson Basin, Southern Arizona, 197 pp., Univ. of Ariz, Tucson, Ariz.

Creutzfeldt, B., A. Guntner, T. Klugel, and H. Wziontek (2008), Simulating the influence of water storage changes on the superconducting gravimeter of the Geodetic Observatory Wettzell, Germany, Geophysics, 73, WA95-WA104, doi:10.1190/1.2992508.

Creutzfeldt, B., T. Ferré, P. Troch, B. Merz, H. Wziontek, and A. Güntner (2012), Total water storage dynamics in response to climate variability and extremes: Inference from long-term terrestrial gravity measurement, J. Geophys. Res., 117, D08112, doi:10.1029/2011JD016472.

Creutzfeldt, B., P. A. Troch, A. Güntner, T. P. A. Ferré, T. Graeff, and B. Merz (2014), Storage-discharge relationships at different catchment scales based on local high-precision gravimetry, Hydrol. Processes, 28, 1465-1475, doi:10.1002/hyp.9689.

Crossley, D., J. Hinderer, and J.-P. Boy (2004), Regional gravity variations in Europe from superconducting gravimeters, J. Geodyn., 38, $325-$ 342, doi:10.1016/j.jog.2004.07.014.

Crossley, D., C. de Linage, J. Hinderer, J.-P. Boy, and J. Famiglietti (2012), A comparison of the gravity field over Central Europe from superconducting gravimeters, GRACE and global hydrological models, using EOF analysis, Geophys. J. Int., 189, 877-897, doi:10.1111/j.1365246X.2012.05404.x.

De Linage, C., J. Hinderer, and Y. Rogister (2007), A search for the ratio between gravity variation and vertical displacement due to a surface load, Geophys. J. Int., 171, 986-994, doi:10.1111/j.1365-246X.2007.03613.x.

Descloitres, M., L. Ruiz, M. Sekhar, A. Legchenko, J.-J. Braun, M. S. Mohan Kumar, and S. Subramanian (2008), Characterization of seasonal local recharge using electrical resistivity tomography and magnetic resonance sounding, Hydrol. Processes, 22, 384-394, doi:10.1002/ hyp.6608.

Descloitres, M., L. Séguis, A. Legchenko, M. Wubda, A. Guyot, and J. M. Cohard (2011), The contribution of MRS and resistivity methods to the interpretation of actual evapotranspiration measurements: A case study in metamorphic context in north Bénin, Near Surf. Geophys., 9(2), 187-200, doi:10.3997/1873-0604.2011003.

Descroix, L., G. Mahé, T. Lebel, G. Favreau, S. Galle, E. Gautier, J. C. Olivry, J. Albergel, O. Amogu, and B. Cappelaere (2009), Spatio-temporal variability of hydrological regimes around the boundaries between Sahelian and Sudanian areas of West Africa: A synthesis, J. Hydrol., 375, 90-102, doi:10.1016/j.jhydrol.2008.12.012.

Deville, S., T. Jacob, J. Chéry, and C. Champollion (2012), On the impact of topography and building mask on time varying gravity due to local hydrology, Geophys. J. Int., 192, 82-93, doi:10.1093/gji/ggs007.

Eckhardt, K. (2005), How to construct recursive digital filters for baseflow separation, Hydrol. Processes, 19, 507-515, doi:10.1002/hyp.5675.

Eckhardt, K. (2008), A comparison of baseflow indices, which were calculated with seven different baseflow separation methods, J. Hydrol., 352, 168-173, doi:10.1016/j.jhydrol.2008.01.005. 
Fannin, R. J., J. Jaakkola, J. M. T. Wilkinson, and E. D. Hetherington (2000), Hydrologic response of soils to precipitation at Carnation Creek, British Columbia, Canada, Water Resour. Res., 36, 1481-1494, doi:10.1029/2000WR900027.

Farr, T. G., et al. (2007), The shuttle radar topography mission, Rev. Geophys., 45, RG2004, doi:10.1029/2005RG000183.

Farrell, W. E. (1972), Deformation of the Earth by surface loads, Rev. Geophys., 10, 761-797, doi:10.1029/RG010i003p00761.

Faure, P. (1977), Carte pédologique de Reconnaissance de la République Populaire du Bénin à 1/200,000, Feuille Djougou, Paris, France.

Faure, P., and B. Volkoff (1998), Some factors affecting regional differentiation of the soils in the Republic of Benin (West Africa), Catena, 32 , 281-306, doi:10.1016/S0341-8162(98)00038-1.

Favreau, G., B. Cappelaere, S. Massuel, M. Leblanc, M. Boucher, N. Boulain, and C. Leduc (2009), Land clearing, climate variability, and water resources increase in semiarid southwest Niger: A review, Water Resour. Res., 45, W00A16, doi:10.1029/2007WR006785.

Ferguson, J. F., T. Chen, J. Brady, C. L. V. Aiken, and J. Seibert (2007), The 4D microgravity method for waterflood surveillance: Part II-Gravity measurements for the Prudhoe Bay reservoir, Alaska, Geophysics, 72, 133-143, doi:10.1190/1.2435473.

Gardelle, J., P. Hiernaux, L. Kergoat, and M. Grippa (2010), Less rain, more water in ponds: A remote sensing study of the dynamics of surface waters from 1950 to present in pastoral Sahel (Gourma region, Mali), Hydrol. Earth Syst. Sci., 14, 309-324, doi:10.5194/hess-14-309-2010.

Gehman, C. L., D. L. Harry, W. E. Sanford, J. D. Stednick, and N. A. Beckman (2009), Estimating specific yield and storage change in an unconfined aquifer using temporal gravity surveys, Water Resour. Res., 45, W00D21, doi:10.1029/2007WR006096.

Gettings, P., D. S. Chapman, and R. Allis (2008), Techniques, analysis, and noise in a Salt Lake Valley 4D gravity experiment, Geophysics, 73, 71, doi:10.1190/1.2996303.

Giertz, S., and B. Diekkrüger (2003), Analysis of the hydrological processes in a small headwater catchment in Benin (West Africa), Phys. Chem. Earth, 28, 1333-1341, doi:10.1016/j.pce.2003.09.009.

Giertz, S., B. Junge, and B. Diekkrüger (2005), Assessing the effects of land use change on soil physical properties and hydrological processes in the sub-humid tropical environment of West Africa, Phys. Chem. Earth, 30, 485-496, doi:10.1016/j.pce.2005.07.003.

Giertz, S., B. Diekkrüger, and G. Steup (2006), Physically-based modelling of hydrological processes in a tropical headwater catchment (West Africa) - Process representation and multi-criteria validation, Hydrol. Earth Syst. Sci., 10, 829-847, doi:10.5194/hess-10-829-2006.

Günther, T. (2004), Inversion methods and resolution analysis for the 2D/3D reconstruction of resistivity structures from DC measurements, TU Bergakademie dissertation, Freiberg, Germany. [Available at http://nbn-resolving.de/urn:nbn:de:swb:105-4152277.] TU Bergakademie, Freiberg, Germany.

Guyot, A., J.-M. Cohard, S. Anquetin, S. Galle, and C. R. Lloyd (2009), Combined analysis of energy and water balances to estimate latent heat flux of a Sudanian small catchment, J. Hydrol., 375, 227-240, doi:10.1016/j.jhydrol.2008.12.027.

Guyot, A., J.-M. Cohard, S. Anquetin, and S. Galle (2012), Long-term observations of turbulent fluxes over heterogeneous vegetation using scintillometry and additional observations: A contribution to AMMA under Sudano-Sahelian climate, Agric. For. Meteorol., 154-155, 8498, doi:10.1016/j.agrformet.2011.10.008.

Hannachi, A., I. T. Jolliffe, and D. B. Stephenson (2007), Empirical orthogonal functions and related techniques in atmospheric science: A review, Int. J. Climatol., 27, 1119-1152, doi:10.1002/joc.1499.

Hasan, S., P. A. Troch, J. Boll, and C. Kroner (2006), Modeling the hydrological effect on local gravity at Moxa, Germany, J. Hydrometeorol., 7, 346-354, doi:10.1175/JHM488.1.

Hector, B. (2011), Caractérisation de la recharge d'une nappe phréatique en contexte sahélien à Diffa (Est-Niger): effets de site incluant poro-élasticité et reprise évapo-transpiratoire, engineering school diploma thesis, 63 pp., Univ. de Strasbourg, Strasbourg, France.

Hector, B. (2014), Caractérisation hydrogéophysique multi-échelles et dynamique des stocks d'eau souterrains d'un bassin versant en zone soudanienne de socle (Bénin): apport de la gravimétrie, 314 pp., Univ. de Strasbourg, Strasbourg, France.

Hector, B., L. Seguis, J. Hinderer, M. Descloitres, J.-M. Vouillamoz, M. Wubda, J.-P. Boy, B. Luck, and N. Le Moigne (2013), Gravity effect of water storage changes in a weathered hard-rock aquifer in West Africa: Results from joint absolute gravity, hydrological monitoring and geophysical prospection, Geophys. J. Int., 194, 737-750, doi:10.1093/gji/ggt146.

Hector, B., J. Hinderer, L. Séguis, J.-P. Boy, M. Calvo, M. Descloitres, S. Rosat, S. Galle, and U. Riccardi (2014), Hydro-gravimetry in West-Africa: First results from the Djougou (Bénin) superconducting gravimeter, J. Geodyn., 80, 34-39, doi:10.1016/j.jog.2014.04.003.

Hinderer, J., C. De Linage, J. P. Boy, P. Gegout, F. Masson, Y. Rogister, M. Amalvict, J. Pfeffer, F. Littel, and B. Luck (2009), The GHYRAF (Gravity and Hydrology in Africa) experiment: Description and first results, J. Geodyn., 48, 172-181, doi:10.1016/j.jog.2009.09.014.

Hinderer, J., et al. (2012), Land water storage changes from ground and space geodesy: First results from the GHYRAF (Gravity and Hydrology in Africa) experiment, Pure Appl. Geophys., 169, 1391-1410, doi:10.1007/s00024-011-0417-9.

Hinderer, J., S. Rosat, M. Calvo, J.-P. Boy, B. Hector, U. Riccardi, and L. Séguis (2014a), Preliminary results from the superconducting gravimeter SG-060 installed in West Africa (Djougou, Benin), in Earth on the Edge: Science for a Sustainable Planet, Int. Assoc. Geod. Symp. 139, edited by C. Rizos and P. Willis, pp. 413-419, Springer, Berlin.

Hinderer, J., B. Hector, J.-P. Boy, U. Riccardi, S. Rosat, M. Calvo, and F. Littel (2014b), A search for atmospheric effects on gravity at different time and space scales, J. Geodyn., 80, 50-57, doi:10.1016/j.jog.2014.02.001.

Hofmann-Wellenhof, B., and H. Moritz (2006), Physical Geodesy, Springer, Wein, Austria.

Howle, J. F., S. P. Phillips, R. P. Denlinger, and L. F. Metzger (2003), Determination of specific yield and water-table changes using temporal microgravity surveys collected during the second injection, storage, and recovery test at Lancaster, Antelope Valley, California, November 1996 through April 1997, 36 pp., U.S. Geol. Surv. Water Resour. Invest., 2003-4019.

Hwang, C., C.-G. Wang, and L.-H. Lee (2002), Adjustment of relative gravity measurements using weighted and datum-free constraints, Comput. Geosci., 28, 1005-1015, doi:10.1016/S0098-3004(02)00005-5.

IAEA (2003), Neutron and Gamma Probes: Their Use in Agronomy, IAEA-TCS, Wein, Austria.

Jackson, J. E. (2004), A User's Guide to Principal Components, John Wiley, Hoboken, N. J.

Jacob, T., R. Bayer, J. Chery, H. Jourde, N. L. Moigne, J.-P. Boy, J. Hinderer, B. Luck, and P. Brunet (2008), Absolute gravity monitoring of water storage variation in a karst aquifer on the larzac plateau (Southern France), J. Hydrol., 359, 105-117, doi:10.1016/j.jhydrol.2008.06.020.

Jacob, T., R. Bayer, J. Chery, and N. Le Moigne (2010), Time-lapse microgravity surveys reveal water storage heterogeneity of a karst aquifer, J. Geophys. Res., 115, B06402, doi:10.1029/2009JB006616.

Jawson, S. D., and J. D. Niemann (2006), Spatial patterns from EOF analysis of soil moisture at a large scale and their dependence on soil, land-use, and topographic properties, Adv. Water Resour., 30, 366-381, doi:10.1016/j.advwatres.2006.05.006.

Jencso, K. G., and B. L. McGlynn (2011), Hierarchical controls on runoff generation: Topographically driven hydrologic connectivity, geology, and vegetation, Water Resour. Res., 47, W11527, doi:10.1029/2011WR010666.

Jolliffe, I. (2005), Principal Component Analysis, John Wiley, Hoboken, N. J.

Judex, M., and H. P. Thamm (2008), IMPETUS Atlas Benin. Research Results 2000-2007, 144 pp., Dep. of Geogr., Univ. of Bonn, Germany. 
Kamagaté, B., L. Séguis, G. Favreau, J.-L. Seidel, M. Descloitres, and P. Affaton (2007), Hydrological processes and water balance of a tropical crystalline bedrock catchment in Benin (Donga, upper Ouémé River), C. R. Geosci., 339, 418-429, doi:10.1016/j.crte.2007.04.003.

Kim, G., and A. P. Barros (2002), Space-time characterization of soil moisture from passive microwave remotely sensed imagery and ancillary data, Remote Sens. Environ., 81, 393-403, doi:10.1016/S0034-4257(02)00014-7.

Kirchner, J. W. (2009), Catchments as simple dynamical systems: Catchment characterization, rainfall-runoff modeling, and doing hydrology backward, Water Resour. Res., 45(2), doi:10.1029/2008WR006912.

Kroner, C., and T. Jahr (2006), Hydrological experiments around the superconducting gravimeter at Moxa Observatory, J. Geodyn., 41, 268275, doi:10.1016/j.jog.2005.08.012.

Kroner, C., and A. Weise (2011), Sensitivity of superconducting gravimeters in central Europe on variations in regional river and drainage basins, J. Geod., 85, 651-659, doi:10.1007/s00190-011-0471-1.

Lachassagne, P., R. Wyns, and B. Dewandel (2011), The fracture permeability of Hard Rock Aquifers is due neither to tectonics, nor to unloading, but to weathering processes, Terra Nova, 23, 145-161, doi:10.1111/j.1365-3121.2011.00998.x.

Lambert, A., and C. Beaumont (1977), Nano variations in gravity due to seasonal groundwater movements: Implications for the gravitational detection of tectonic movements, J. Geophys. Res., 82, 297-306, doi:10.1029/JB082i002p00297.

Lampitelli, C., and O. Francis (2010), Hydrological effects on gravity and correlations between gravitational variations and level of the Alzette River at the station of Walferdange, Luxembourg, J. Geodyn., 49, 31-38, doi:10.1016/j.jog.2009.08.003.

Le Lay, M., and S. Galle (2005), Seasonal cycle and interannual variability of rainfall at hydrological scales. The West African monsoon in a Sudanese climate, Hydrol. Sci. J., 50, 509-524, doi:10.1623/hysj.50.3.509.65029.

Leake, S. A. (2011), Capture-Rates and directions of groundwater flow don't matter!, Ground Water, 49, 456-458, doi:10.1111/j.17456584.2010.00797.x

Lebel, T., et al. (2009), AMMA-CATCH studies in the Sahelian region of West-Africa: An overview, J. Hydrol., 375, 3-13, doi:10.1016/ j.jhydrol.2009.03.020.

Lebel, T., and T. Vischel (2005), Climat et cycle de l'eau en zone tropicale : un problème d'échelle, C. R. Geosci., 337, 29-38, doi:10.1016/ j.crte.2004.08.011.

Leblanc, M. J., G. Favreau, S. Massuel, S. O. Tweed, M. Loireau, and B. Cappelaere (2008), Land clearance and hydrological change in the Sahel: SW Niger, Global Planet. Change, 61, 135-150, doi:10.1016/j.gloplacha.2007.08.011.

Leirião, S., X. He, L. Christiansen, O. B. Andersen, and P. Bauer-Gottwein (2009), Calculation of the temporal gravity variation from spatially variable water storage change in soils and aquifers, J. Hydrol., 365, 302-309, doi:10.1016/j.jhydrol.2008.11.040.

Mahé, G., and J.-E. Paturel (2009), 1896-2006 Sahelian annual rainfall variability and runoff increase of Sahelian Rivers, C. R. Geosci., 341, 538-546, doi:10.1016/j.crte.2009.05.002.

Mamadou, O., J. M. Cohard, S. Galle, C. N. Awanou, A. Diedhiou, B. Kounouhewa, and C. Peugeot (2014), Energy fluxes and surface characteristics over a cultivated area in Benin: Daily and seasonal dynamics, Hydrol. Earth Syst. Sci., 18, 893-914, doi:10.5194/hess-18-893-2014.

Masiyandima, M. C., N. van de Giesen, S. Diatta, P. N. Windmeijer, and T. S. Steenhuis (2003), The hydrology of inland valleys in the sub-humid zone of West Africa: Rainfall-runoff processes in the M'bé experimental watershed, Hydrol. Processes, 17, 1213-1225, doi:10.1002/hyp.1191.

Masson, F., D. Viville, M.-C. Pierret, M. Mouyen, L. Hecker, and F. Chabaux (2012), Time-lapse microgravity study of the Strengbach catchment (Vosges mountains, France), C. R. Geosci., 344, 357-365, doi:10.1016/j.crte.2012.06.001.

McClymont, A. F., M. Hayashi, L. R. Bentley, and J. Liard (2012), Locating and characterising groundwater storage areas within an alpine watershed using time-lapse gravity, GPR and seismic refraction methods, Hydrol. Processes, 26, 1792-1804, doi:10.1002/hyp.9316.

McNamara, J. P., D. Tetzlaff, K. Bishop, C. Soulsby, M. Seyfried, N. E. Peters, B. T. Aulenbach, and R. Hooper (2011), Storage as a metric of catchment comparison, Hydrol. Processes, 25, 3364-3371, doi:10.1002/hyp.8113.

Merlet, S., A. Kopaev, M. Diament, G. Geneves, A. Landragin, and F. P. D. Santos (2008), Micro-gravity investigations for the LNE watt balance project, Metrologia, 45, 265, doi:10.1088/0026-1394/45/3/002.

Merriam, J. B. (1992), Atmospheric pressure and gravity, Geophys. J. Int., 109, 488-500, doi:10.1111/j.1365-246X.1992.tb00112.x.

Metzger, L. F., M. E. Ikehara, J. F. Howle (2002), Vertical-deformation, water-level, microgravity, geodetic, water-chemistry, and flow-rate data collected during injection, storage, and recovery tests at Lancaster, Antelope Valley, California, September 1995 through September 1998, U.S. Geol. Surv. Open File Rep., 2001-414, 164 pp.

Meurers, B., M. Camp, and T. Petermans (2007), Correcting superconducting gravity time-series using rainfall modelling at the Vienna and Membach stations and application to Earth tide analysis, J. Geod., 81, 703-712, doi:10.1007/s00190-007-0137-1.

Miguez-Macho, G., and Y. Fan (2012), The role of groundwater in the Amazon water cycle: 1. Influence on seasonal streamflow, flooding and wetlands, J. Geophys. Res., 117, D15113, doi:10.1029/2012JD017539.

Montgomery, E. L. (1971), Determination of coefficient of storage by use of gravity measurements, PhD thesis, The Univ. Ariz, Tucson, Ariz.

Mouyen, M., F. Masson, C. Hwang, C. C. Cheng, N. Le Moigne, R. Kao, and W. C. Hsieh (2013), Erosion effects assessed by repeated gravity measurements in southern Taiwan, Geophys. J. Int., 192(1), 113-136, doi:10.1093/gji/ggs019.

Naujoks, M., A. Weise, C. Kroner, and T. Jahr (2008), Detection of small hydrological variations in gravity by repeated observations with relative gravimeters, J. Geod., 82, 543-553, doi:10.1007/s00190-007-0202-9.

Naujoks, M., C. Kroner, A. Weise, T. Jahr, P. Krause, and S. Eisner (2010), Evaluating local hydrological modelling by temporal gravity observations and a gravimetric three-dimensional model, Geophys. J. Int., 182, 233-249, doi:10.1111/j.1365-246X.2010.04615.x.

Neumeyer, J., F. Barthelmes, C. Kroner, S. Petrovic, R. Schmidt, H. Virtanen, and H. Wilmes (2008), Analysis of gravity field variations derived from Superconducting Gravimeter recordings, the GRACE satellite and hydrological models at selected European sites, Earth Planets Space, 60, 505-518.

Noguchi, S., A. R. Nik, Z. Yusop, M. Tani, and T. Sammori (1997), Rainfall-runoff responses and roles of soil moisture variations to the response in tropical rain forest, Bukit Tarek, Peninsular Malaysia, J. For. Res., 2, 125-132, doi:10.1007/BF02348209.

Okubo, S., M. Satomura, M. Furuya, W. Sun, S. Matsumoto, S. Ueki, and H. Watanabe (2002), Grand design for the hybrid gravity network around the Mt. Fuji volcano, in International Symposium on Geodesy in Kanazawa Abstract, pp. 39-40, International Symposium on Geodesy Kanazawa, Japan.

Perry, M. A., and J. D. Niemann (2007), Analysis and estimation of soil moisture at the catchment scale using EOFs, J. Hydrol., 334, 388-404, doi:10.1016/j.jhydrol.2006.10.014.

Perry, M. A., and J. D. Niemann (2008), Generation of soil moisture patterns at the catchment scale by EOF interpolation, Hydrol. Earth Syst. Sci., 12, 39-53, doi:10.5194/hess-12-39-2008.

Pfeffer, J. (2011), Étude du cycle de l'eau en Afrique sahélienne : Approche multidisciplinaire et apport de la gravimétrie terrestre et spatiale, Thèse de doctorat, Univ. de Strasbourg, Strasbourg, France. 
Pfeffer, J., et al. (2013), Evaluating surface and subsurface water storage variations at small time and space scales from relative gravity measurements in semi-arid Niger, Water Resour. Res., 49, 3276-3291, doi:10.1002/wrcr.20235.

Pool, D. R. (2008), The utility of gravity and water-level monitoring at alluvial aquifer wells in southern Arizona, Geophysics, 73, WA49WA59, doi:10.1190/1.2980395

Pool, D. R., and M. T. Anderson (2008), Ground-water storage change and land subsidence in Tucson Basin and Avra Valley, Southeastern Arizona, 1998-2002, 44 pp., U.S. Geol. Surv. Sci. Invest. Rep., 2007-5275.

Pool, D. R., and J. H. Eychaner (1995), Measurements of aquifer-storage change and specific yield using gravity surveys, Ground Water, 33 , 425-432, doi:10.1111/j.1745-6584.1995.tb00299.x.

Pool, D. R., D. Winster, and K. C. Cole (2000), Land-subsidence and ground-water storage monitoring in the Tucson Active Management Area, Arizona, U.S. Geol. Surv. Fact Sheet, 084-00, 4 pp.

Preisendorfer, R. W., and C. D. Mobley (1988), Principal Component Analysis in Meteorology and Oceanography, Elsevier, Amsterdam.

Rabier, F., H. Järvinen, E. Klinker, J.-F. Mahfouf, and A. Simmons (2000), The ECMWF operational implementation of four-dimensional variational assimilation. I: Experimental results with simplified physics, Q. J. R. Meteorol. Soc., 126, 1143-1170, doi:10.1002/qj.49712656415.

Raunet, M. (1985), Bas-fonds et riziculture en Afrique: Approche structural comparative, Agron. Trop., 40, 181-201.

Richard, A. (2014), Analyse du cycle hydrologique en climat soudanien au Bénin: vers une modélisation couplée des processus latéraux et verticaux, Thèse de doctorat, Univ. de Grenoble, Grenoble, France.

Richard, A., S. Galle, M. Descloitres, J.-M. Cohard, J.-P. Vandervaere, L. Séguis, and C. Peugeot (2013), Interplay of riparian forest and groundwater in the hillslope hydrology of Sudanian West Africa (northern Benin), Hydrol. Earth Syst. Sci., 17, 5079-5096, doi:10.5194/hess-175079-2013.

Robert, D. (2012), Caractérisation et modélisation de la dynamique de l'évapotranspiration en Afrique soudanienne en zone de socle, Thèse de doctorat, 255 pp., Univ. de Grenoble, Grenoble, France.

Romagnoli, C., S. Zerbini, L. Lago, B. Richter, D. Simon, F. Domenichini, C. Elmi, and M. Ghirotti (2003), Influence of soil consolidation and thermal expansion effects on height and gravity variations, J. Geodyn., 35, 521-539, doi:10.1016/S0264-3707(03)00012-7.

Seaton, W. J., and T. J. Burbey (2002), Evaluation of two-dimensional resistivity methods in a fractured crystalline-rock terrane, J. Appl. Geophys., 51, 21-41, doi:10.1016/S0926-9851(02)00212-4.

Séguis, L., B. Cappelaere, G. Milési, C. Peugeot, S. Massuel, and G. Favreau (2004), Simulated impacts of climate change and land-clearing on runoff from a small Sahelian catchment, Hydrol. Processes, 18, 3401-3413, doi:10.1002/hyp.1503.

Séguis, L., et al. (2011a), Contrasted land-surface processes along the West African rainfall gradient, Atmos. Sci. Lett., 12, 31-37, doi:10.1002/ asl.327.

Séguis, L., et al. (2011b), Origins of streamflow in a crystalline basement catchment in a sub-humid Sudanian zone: The Donga basin (Benin, West Africa): Inter-annual variability of water budget, J. Hydrol., 402, 1-13, doi:10.1016/j.jhydrol.2011.01.054.

Seibert, J., K. Bishop, L. Nyberg, and A. Rodhe (2011), Water storage in a till catchment. I: Distributed modelling and relationship to runoff, Hydrol. Processes, 25, 3937-3949, doi:10.1002/hyp.8309.

Seigel, H. O., I. Brcic, and P. Mistry (1995), A Guide to High Precision Land Gravimeter Surveys, Scintrex Ltd., Concord, Ont., Canada.

Spence, C. (2010), A paradigm shift in hydrology: Storage thresholds across scales influence catchment runoff generation, Geogr. Compass, 4, 819-833, doi:10.1111/j.1749-8198.2010.00341.x.

Sugihara, M., and T. Ishido (2008), Geothermal reservoir monitoring with a combination of absolute and relative gravimetry, Geophysics, 73 , WA37-WA47, doi:10.1190/1.2991105.

Tetzlaff, D., J. P. McNamara, and S. K. Carey (2011), Measurements and modelling of storage dynamics across scales, Hydrol. Processes, 25, 3831-3835, doi:10.1002/hyp.8396.

Torge, W. (1980), Geodesy, Walter de Gruyter, Berlin

Tromp-van Meerveld, H. J., and J. J. McDonnell (2006), Threshold relations in subsurface stormflow: 2 . The fill and spill hypothesis, Water Resour. Res., 42, W02411, doi:10.1029/2004WR003800.

Valentin, C., J.-L. Rajot, and D. Mitja (2004), Responses of soil crusting, runoff and erosion to fallowing in the sub-humid and semi-arid regions of West Africa, Agric. Ecosyst. Environ., 104, 287-302, doi:10.1016/j.agee.2004.01.035.

Van Camp, M., M. Vanclooster, O. Crommen, T. Petermans, K. Verbeeck, B. Meurers, T. Van Dam, and A. Dassargues (2006), Hydrogeological investigations at the Membach station, Belgium, and application to correct long periodic gravity variations, J. Geophys. Res., 111, B10403, doi:10.1029/2006JB004405.

Van De Giesen, N. C., T. J. Stomph, and N. de Ridder (2000), Scale effects of Hortonian overland flow and rainfall-runoff dynamics in a West African catena landscape, Hydrol. Processes, 14, 165-175, doi:10.1002/(SICI)1099-1085(200001)14:1 < 165::AID-HYP920> 3.0.CO;2-1.

Vandervaere, J. P., M. Vauclin, R. Haverkamp, and R. H. Cuenca (1994), Error analysis in estimating soil water balance of irrigated fields during the EFEDA experiment: 1. Local standpoint, J. Hydrol., 156, 351-370, doi:10.1016/0022-1694(94)90085-X.

Verhoest, N. E. C., P. A. Troch, C. Paniconi, and F.P. De Troch (1998), Mapping basin scale variable source areas from multitemporal remotely sensed observations of soil moisture behavior, Water Resour. Res., 34, 3235-3244, doi:10.1029/98WR02046.

Vollmert, P., A. H. Fink, and H. Besler (2003), “Ghana Dry Zone" und "Dahomey Gap": Ursachen für eine Niederschlagsanomalie im tropischen Westafrika, Erde, 134, 375-393.

Vouillamoz, J. M., F. M. A. Lawson, N. Yalo, and M. Descloitres (2015), Groundwater in hard rocks of Benin: Regional storage and buffer capacity in the face of change, J. Hydrol., 520, 379-386, doi:10.1016/j.jhydrol.2014.11.024.

Whitcomb, J. H., W. O. Franzen, J. W. Given, J. C. Pechmann, and L. J. Ruff (1980), Time-dependent gravity in southern California, May 1974 to April 1979, J. Geophys. Res., 85, 4363-4373, doi:10.1029/JB085iB08p04363.

Yoo, C., and S. Kim (2004), EOF analysis of surface soil moisture field variability, Adv. Water Resour., 27, 831-842, doi:10.1016/ j.advwatres.2004.04.003. 